\title{
A fuzzy evidential reasoning-based approach for risk assessment of
}

\section{deep foundation pit}

\author{
Daojiang Wei ${ }^{\mathrm{a}} \quad$ Dongsheng $\mathrm{Xu}^{\mathrm{b}^{*}} \quad$ Yong Zhang $^{\mathrm{c}}$ \\ ( ${ }^{a}$ School of Civil Engineering and Architecture, Hubei University of art and science, Xiangyang Hubei \\ 441053, China; ${ }^{b}$ Salford Business School, the University of Salford, UK ; ${ }^{c}$ School of Civil Engineering, Xi'an \\ University of Architecture and Technology, Xi'an Shaanxi 710055, China)
}

Abstract: Traditional risk assessment methods, such as the probabilistic methods, are not effectively used in the construction works of a deep foundation pit (DFP) when data set collected are incomplete or vague input takes place. A new method based on fuzzy evidential reasoning approach is proposed in this paper to assess the overall risk level of a DFP construction project. Firstly, the method defines risks as the products of occurrence likelihood multiplying consequence severity, which is further depicted by trapezoidal fuzzy numbers. Thereafter, the fuzzy analytical hierarchy process is adopted to calculate the weighs of different hazardous events that may occur in a DFP construction project. The overall risk level of a DFP project therefore could be achieved through aggregating the risk level of all hazardous events based on evidential reasoning algorithm. However, due to the existence of intersections among more than two continuous fuzzy evaluation grades rather than between two adjacent grades, the prevailing aggregation method is not suitable any more. So, a new aggregated probability mass along with the reassigning method in relation to the degree of belief belonging to the fuzzy intersection of two grades is thus put forward in this paper, as a result to make the evidential reasoning possible. A case study on risk assessment of the DFP of underground traffic project of Zhengzhou comprehensive transportation hub in China is introduced to illustrate the application of the proposed method. The result indicates that the overall risk level of a DFP project could be assessed effectively under the scenario that more than two continuous fuzzy evaluation grades intersect rather than only two adjacent grades. Moreover, comparing with the traditional methods, the result obtained in the case study by using the proposed method seems to be more reasonable. 
27 Keywords: deep foundation pit; risk assessment; fuzzy set theory; evidential reasoning; fuzzy analytical hierarchy process

\section{Introduction}

The risk management of DFP in the construction stage attracts widespread attention in the construction industry ( $\mathrm{Li}$ et al., 2018; Xiong et al., 2018). According to the definition of risk management in the Subway and Underground Engineering Construction Risk Management Guidelines developed by Ministry of Construction, People's Republic of China (MoC, 2007), the risk management of DFP in the construction stage consists of two parts: risk assessment and risk control. Of which, the risk assessment is further divided into risk identification, risk analysis, and risk evaluation. Whether the construction risk of DFP can be assessed timely and objectively is not only related to the rationality of risk control, but also to the safety of DFP per se and the effectiveness of the protection measures on the surrounding environment of the DFP. Since the information available for risk assessment, including geotechnical parameters and hydrographical condition, are usually of uncertainty and incompleteness, a series of fuzzy methods were employed to assess the risk of DFP construction in previous researches. For example, a formalized procedure and a fuzzybased risk assessment method developed by Choi et al. (2004); a fuzzy comprehensive evaluation model based on Bayesian network proposed by Zhou and Zhang (2011); and a hybrid framework integrating step-wise weight assessment ratio analysis with complex proportional assessment (Valipour et al., 2017). The common feature of the above approaches is that, the occurrence likelihood (L) and the consequence severity (S), the two parameters which measure the magnitude of risks that may happen, are usually estimated by risk assessors' human scoring. However, assessors are more likely to make qualitative assessments in the linguistic terms rather than precise scores. Therefore, the research of risk assessment for the construction of DFP under the linguistic environment keeps closer to the needs of construction practice. Moreover, since the risk assessment results are often exhibited in certain values in previous research, the extent to which the certain values are reliable is unrevealed.

Evidential reasoning (ER) is a method of evidence fusion proposed by Yang and $\mathrm{Xu}$ (2002) on the basis of evidence theory, which could be used to illustrate incomplete information directly and 
to deal with problems of assessment in the linguistic environment. The assessment result obtained using ER is a set of degree of beliefs associated with a predefined frame of discernment. In recent years, a number of scholars elaborated to combine ER with fuzzy set theory, which is usually called as fuzzy evidential reasoning (FER) approach, to carry out a systematic risk assessment. For example, a semi quantitative approach based on FER was proposed by Deng et al. (2011) and Liu et al. (2005) to perform risk analysis for complex systems due to lack of data and insufficient understanding of the failure mechanisms; a risk assessment model based on FER was adopted by Mokhtari et al. (2012), Yang \& Wang (2015) and Zhang et al. (2016) owing to the objective data is sometimes incomplete in offshore engineering system; in the presence of multiple experts supplying different and uncertain judgments on risk parameters, Certa et al. (2017) conducted a failure mode and related effects analysis using FER; John et al. (2014) built a model based on FER to solve the problem of risk assessment of seaport operations in a fuzzy uncertain environment. The main shortcoming of the present researches is that only the intersection between two adjacent fuzzy evaluation grades is considered, however, in fact, there may exist the scenario that more than two continuous fuzzy evaluation grades intersect rather than only two adjacent grades.

In the field of DFP construction, Du et al. ( 2014) and Cheng et al. ( 2016) have ever tried to apply evidence theory to the field of risk assessment of DFP construction, but there exists some defects which need to be addressed. For example, in Du et al. ( 2014)'s application, the interrelationship among risk evaluation grades was not considered, which may lead to counterintuitive results (Yang \& $\mathrm{Xu}, 2013$ ). After all, the evidence theory is based on a frame of discernment composed of a set of propositions that are mutually exclusive and collectively exhaustive (Shafer, 2016). With respect to Cheng et al. (2016)' application, it is unreasonable to use occurrence probability (likelihood) only rather than the product of occurrence likelihood and consequence severity as the basis for risk assessment.

A new method with respect to risk assessment for DFP construction based on FER is put forward in this paper. In the proposed method, risks are defined as the products of occurrence likelihood multiplying consequence severity; and, the scenario that more than two continuous fuzzy evaluation grades intersect rather than only two adjacent grades is depicted.

The remainder of this paper is organized as follows: Section 2 briefs the theoretical basis of the 
method; Section 3 describes how the risk data of DFP were obtained by assessors; using FER, the risk assessment model of DFP construction is established in Section 4; Section 5 conducts validating analysis about the applicability of the method through a case study; and, further discussion is delivered in in Section 6, conclusions of this paper are drawn in Section 7.

\section{Theoretical Bases}

\subsection{Fuzzy Set Theory}

Fuzzy set theory Zadeh (1965) is a generalization of classical set theory. Compared with classical set theory, fuzzy set theory could deal with the uncertain phenomenon relating to the rationale of 'both this and that' rather than the one of 'if not this, then that'. So far, it has been popularized in model identification (Certa et al., 2017; Jiang et al., 2017; Kim \& Zuo, 2018; Liu et al., 2011; Liu et al., 2013; Liu et al., 2013), risk assessment (An et al., 2011; An et al., 2016), and uncertainty decision-making (Mokhtari et al., 2012). In different DFP construction stages, the information available for risk assessment is often incomplete and vague owing not only to the uncertain geological and hydrological conditions but also the complicated surrounding environment. Thereby, the linguistic terms, such as 'likely' and 'frequent' are usually employed to express the risk judgements from the risk assessors. Under such circumstance, the fuzzy set theory is a useful tool which through converting the assessors' subjective judgements into fuzzy numbers to quantify risk assessments. In general, there are two kinds of fuzzy numbers usually adopted, namely, triangular fuzzy number and trapezoidal fuzzy number. Since the former could be regarded as the special case of the latter, the trapezoidal fuzzy number is employed in this paper, as shown in Fig.1.

Where $\mu_{A}(x)$ represents the membership of $x$ to $A$, and which is defined as:

$$
\mu_{A}(x)=\left\{\begin{array}{lc}
(x-a) /(b-a), & x \in(a, b) \\
1 & x \in[b, c] \\
(d-x) /(d-c), & x \in(c, d) \\
0 & \text { otherwise }
\end{array}\right.
$$

In which, $a$ denotes the pessimistic rating, $b$ and $c$ are two endpoints of the interval which denotes the most plausible rating, $d$ denotes the optimistic rating ( $\mathrm{Li} \&$ Liao, 2007).

\subsection{FER}

FER is the extension to the original ER approach, which is proposed by Yang et al. (2006) to deal 
with the vagueness or fuzzy uncertainty in fuzzy assessment issues where the evaluation grades are no longer distinctive individual grades, but are dependent fuzzy grades. Suppose that the assessment object is evaluated at the $\tilde{L}$ attributes on the basis of $N$ evaluation grades $H_{n}(n=1,2, \ldots, N)$, and the relative weights of the $\tilde{L}$ attributes are denoted by $\omega=\left(\omega_{1}, \omega_{2}, \ldots, \omega_{\tilde{L}}\right)$, which are normalized to satisfy the condition: $0 \leq \omega_{j} \leq 1$ and $\sum_{j=1}^{\tilde{L}} \omega_{j}=1$. The evaluation grades $H_{n}$ are not independent from each other due to the expression using a linguistic form, such as 'critical' and 'very critical', then $H_{n}$ can be labeled with fuzzy evaluation grades which are trapezoidal fuzzy sets in this research. In general, only the intersection between two adjacent fuzzy evaluation grades is considered, which can be depicted as Fig. 2.

There are often three steps to conduct fuzzy assessment using FER approach as follows:

- Converting the evaluated values, which are generated from risks assessors' judgement originally and expressed as trapezoidal fuzzy number uniformly then, into a belief structure denoted by $S\left(e_{j}\right)=\left\{\left(H_{n}, \beta_{n, j}\right), n=1,2, \cdots, N\right\}$. In which, $e_{j}(j=1,2, \cdots, \tilde{L})$ is attribute and $\beta_{n, j}$ is the degree of belief which refers to the evaluation object assessed to a grade $H_{n}$ on an attribute $e_{j}$, and meets the conditions as follows: $\beta_{n, j} \geq 0$ and $\sum_{n=1}^{N} \beta_{n, j} \leq 1$.

- Aggregating all the evidences in terms of belief structure using analytical (non-recursive) FER algorithm, so that the aggregated degree of belief $\beta_{n}$ and $\beta_{n,(n+1)}$ could be calculated respectively.

- Redistributing $\beta_{n,(n+1)}$ into $\beta_{n}$ and $\beta_{n+1}$, and finally the fuzzy assessment result which is denoted by $S($ Object $)=\left\{\left(H_{n}, \beta_{n}\right), n=1,2, \ldots, N\right\}$ could be arrived.

The detail of FER algorithm and the procedure of redistribution with respect to $\beta_{n,(n+1)}$ are omitted in this paper due to the consideration of brevity. Interested reader will get reference from Yang et al. (2006).

\section{Preparation works for risk assessment}

3.1 Allocation of expert indices to risk assessment 
The complicated process of risk assessment on a DFP project enables few cases can be completed by a single assessor (expert). In practice, a number of experts with different backgrounds or domains in relation to DFP safety are usually involved in the risk assessment. Considering the different working experience and knowledge background of experts, the influence of individual expert on the overall decision-making results is different. Therefore, the concept of expert index (EI) is introduced to calculate the influence of expertise (An et al., 2011).

Definition 1: Expert index refers to the measurement of the influence of individual expert on the group decision-making results, which can be denoted by:

$$
E I_{\tilde{i}}=\frac{R I_{\tilde{i}}}{\sum_{\tilde{i}=1}^{m} R I_{\tilde{i}}}
$$

Where $m$ is the number of experts involved in the risk assessment, $R I_{\tilde{i}}$ stands for the relevant importance of the $\tilde{i t h}$ expert according to his experience, knowledge, and expertise, which takes a value in the universe of 1 to $9 . \quad R I$ is defined in a manner that ' 1 ' means less importance, whereas '9' means most importance (An et al., 2011).

3.2 Development of a risk framework

Many possible causes of risks may impact DFP safety. Developing a risk framework aims to decompose these risk contributors into adequate details in which different risks associated with a DFP construction could be efficiently assessed (An et al., 2011; An et al., 2016). A bottom-up approach is employed for the development of a risk framework. That is, through experts brainstorming, the hazardous events related to the construction of a DFP are numerated to the utmost, and then, the risks that may arise from the hazardous events are categorized on a layer-bylayer basis until the top layer of the risks framework is received. Typically, a risk framework of DFP breaks down into four layers: the hazardous event level, the hazard group level, the sub-object level, and the total object level (depicted in Fig. 3).

\subsection{Acquisition of the risk level of the hazardous events} likelihood (frequency) and consequence severity (impact) that may affect the risk level of every hazardous event. A common demonstration of risk level is simply to multiply the occurrence 


\section{Table2.}

likelihood by consequence severity, which can be illustrated as:

$$
R=L \times S
$$

While $R$ refers to the risk level of each hazardous event, $L$ represents its occurrence likelihood and $S$ represents the consequence severity. Since the information available for risk assessment is often incomplete and vague owing not only to the uncertain geological and hydrological conditions but to the complicated surrounding environment, it is more reasonable to ask experts for fuzzy instead precise risk assessment using qualitative linguistic variables. To measure the occurrence likelihood, for example, the qualitative scales such as being unlikely, infrequent, occasional, likely and frequent could be used. Likewise, the scales of being negligible, marginal, moderate, critical, and catastrophic could be adopted to assess the consequence severity.

Going further, the trapezoidal fuzzy number is selected to depict the aforementioned qualitative scales with the satisfaction of three properties: available domain knowledge, simplicity of the membership function, and possible parametric optimization of the fuzzy sets (Samantra et al., 2017; Yuen, 2014). Thus, according to $\mathrm{MoC}$ (2007), the classification criteria of each grade with respect to the occurrence likelihood and the consequence severity are shown respectively in Table 1 and

Table 1 The classification criteria of occurrence likelihood

\begin{tabular}{cccc}
\hline Grade & $\begin{array}{c}\text { Linguistic } \\
\text { description }\end{array}$ & Numerical values & Membership function \\
\hline 1 & Unlikely & $0-0.01 \%$ & $\{0,0,5.0 E-5,1.0 E-4\}$ \\
2 & Infrequent & $0.01 \%-0.1 \%$ & $\{5.0 E-5,1.0 E-4,1.0 E-3,5.5 E-3\}$ \\
3 & Occasional & $0.1 \%-1 \%$ & $\{1.0 E-3,5.5 E-3,1.0 E-2,5.5 E-2\}$ \\
4 & Likely & $1 \%-10 \%$ & $\{1.0 E-2,5.5 E-2,1.0 E-1,5.5 E-1\}$ \\
5 & Frequent & $10 \%-1.0$ & $\{1.0 E-1,5.5 E-1,1.0,1.0\}$ \\
\hline
\end{tabular}

Table 2 The classification criteria of consequence severity

\begin{tabular}{cccc}
\hline Grade & Linguistic description & Numerical values* & Membership function \\
\hline 1 & Negligible & $0-500$ & $\{0,0,250,500\}$
\end{tabular}




$\begin{array}{lccc}2 & \text { Marginal } & 500-1000 & \{250,500,1000,3000\} \\ 3 & \text { Moderate } & 1000-5000 & \{1000,3000,5000,7500\} \\ 4 & \text { Critical } & 5000-10000 & \{5000,7500,10000,55000\} \\ 5 & \text { Catastrophic } & >10000 & \{10000,55000,100000,100000\}\end{array}$

181

182

183

Note*: according to MoC (2007), consequence severity can be represented by a variety of forms. But in this paper, only the form of direct economic losses is adopted (Unit: ten thousands RMB)

In addition, Table 3 represents the risk matrices (risk grade: I to V) derived from the combination of $L$ and $S$, which are universally applied in China.

Table 3 The risk matrix derived from the combination of $L$ and $S$

\begin{tabular}{|c|c|c|c|c|c|c|}
\hline & & \multicolumn{5}{|c|}{ Consequence severity } \\
\hline & & Negligible & $\begin{array}{c}\text { Margina } \\
1\end{array}$ & Moderate & Critical & Catastrophic \\
\hline \multirow{5}{*}{ Occurrence Likelihood } & Unlikely & $\bar{I}$ & I & II & III & IV \\
\hline & Infrequent & I & II & III & III & IV \\
\hline & Occasional & I & II & III & IV & $\mathrm{V}$ \\
\hline & Likely & II & III & IV & IV & $\mathrm{V}$ \\
\hline & Frequent & II & III & IV & $\mathrm{V}$ & $\mathrm{V}$ \\
\hline
\end{tabular}

Based on the aforementioned classification criterions, the assessment of occurrence likelihood and consequence severity of each hazard in Fig. 3 could be conducted as follows:

Suppose that there are $m$ experts involved in risk evaluation of a DFP construction. With respect to an individual hazard $j$, the occurrence likelihood assessed by $\tilde{i}$ th expert is denoted by $L_{j}^{\tilde{i}}=\left\{L_{j, a}^{\tilde{i}}, L_{j, b}^{\tilde{i}}, L_{j, c}^{\tilde{i}}, L_{j, d}^{\tilde{i}}\right\}$, where $\tilde{i}=1,2, \ldots, m$ and $j=1,2, \ldots, \tilde{L}$. Then the aggregated occurrence likelihood of hazard $j$ could be determined by:

$$
L_{j}=\left\{\frac{\sum_{\tilde{i}=1}^{m} E I_{\tilde{i}} \times L_{j, a}^{\tilde{i}}}{\sum_{i=1}^{m} E I_{\tilde{i}}}, \frac{\sum_{i=1}^{m} E I_{\tilde{i}} \times L_{j, b}^{\tilde{i}}}{\sum_{i=1}^{m} E I_{\tilde{i}}}, \frac{\sum_{\tilde{i}=1}^{m} E I_{\tilde{i}} \times L_{j, c}^{\tilde{i}}}{\sum_{i=1}^{m} E I_{\tilde{i}}}, \frac{\sum_{i=1}^{m} E I_{\tilde{i}} \times L_{j, d}^{\tilde{i}}}{\sum_{i=1}^{m} E I_{\tilde{i}}}\right\}
$$

Herein $E I_{\tilde{i}}$ stands for the $\tilde{i}$ th expert's $E I$.

Similarly, the consequence severity of hazard $j$ could be obtained by: 


$$
S_{j}=\left\{\frac{\sum_{\tilde{i}=1}^{m} E I_{\tilde{i}} \times S_{j, a}^{\tilde{i}}}{\sum_{\tilde{i}=1}^{m} E I_{\tilde{i}}}, \frac{\sum_{\tilde{i}=1}^{m} E I_{\tilde{i}} \times S_{j, b}^{\tilde{i}}}{\sum_{\tilde{i}=1}^{m} E I_{\tilde{i}}}, \frac{\sum_{\tilde{i}=1}^{m} E I_{\tilde{i}} \times S_{j, c}^{\tilde{i}}}{\sum_{\tilde{i}=1}^{m} E I_{\tilde{i}}}, \frac{\sum_{\tilde{i}=1}^{m} E I_{\tilde{i}} \times S_{j, d}^{\tilde{i}}}{\sum_{\tilde{i}=1}^{m} E I_{\tilde{i}}}\right\}
$$

Subsequently, the value-at-risk of hazard $j$ could be calculated by Eq. (3). It is worth noting that the same level of risk corresponds to multiple value-at-risks in Table 3. Since these value-at-risks are all trapezoidal fuzzy numbers, the universe of discourse will be overlapped with each other inevitably. This paper proposes to integrate the overlapped state into a uniform frame, as a result, one single risk level corresponds to only one fuzzy number.

Suppose that the $n t h$ grade of the risk is represented by $H_{n}(n=1,2, \ldots, 5) . H_{n}$ could be obtained from the combinations of $l$ sets of occurrence likelihood and $s$ sets of consequence severity, where $1 \leq l \leq 5,1 \leq s \leq 5$, and both are integers. Thereby the $H_{n}$ is expressed as trapezoidal fuzzy number as:

$$
\begin{aligned}
H_{n} & =\left\{R_{a}, R_{b}, R_{c}, R_{d}\right\} \\
& =\left\{\min \left(\left[L_{l i, a} \otimes S_{s i, a}\right]\right), \frac{\left[\sum_{l i=1}^{l} \sum_{s i=1}^{s} L_{l i, b} \otimes S_{s i, b}\right]}{[l \times s]}, \frac{\left.\sum_{l i=1}^{l} \sum_{s i=1}^{s} L_{l i, c} \otimes S_{s i, c}\right]}{[l \times s]}, \max \left(\left[L_{l i, d} \otimes S_{s i, d}\right]\right)\right\}
\end{aligned}
$$

$$
\text { In Eq. (6), '[ ] 'refers to the selection of the valid combinations only, because not all of the }
$$
combinations should be classified as $H_{n}$. For example, when calculating the risk grade 'I' in Table 3, six results are generated from pairwise multiplications of three sets of occurrence likelihood i.e. $L_{1}, \quad L_{2}$ and $L_{3}$ respectively, and two sets of consequence severity i.e. $S_{1}$ and $S_{2}$. However, four out of the six results which fall into the scope of risk grade 'I' are regarded as valid combinations: $L_{1} \otimes S_{1}, L_{1} \otimes S_{2}, \quad L_{2} \otimes S_{1}$, and $L_{3} \otimes S_{1}$. The relationship between risk grade and the corresponding membership function which could be built up through Eq. (6) are shown in Table 4.

Table 4 The relationship between risk grades and the corresponding membership function

\begin{tabular}{llcc}
\hline Grade* & $\begin{array}{c}\text { Linguistic } \\
\text { description }\end{array}$ & Control scheme & Membership function \\
\hline$H_{1}(\mathrm{I})$ & Negligible & To conduct routine management and & $\{0,0,0.14,2.75\}$
\end{tabular}




\begin{tabular}{|c|c|c|c|}
\hline & & monitoring & \\
\hline$H_{2}$ ( II ) & Slight & $\begin{array}{l}\text { To strengthen the routine management and } \\
\text { examinations }\end{array}$ & $\{0,0.07,2.8,41.25\}$ \\
\hline$H_{3}$ (III) & Need-Consider & $\begin{array}{l}\text { To rule with preventive and monitoring } \\
\text { measures }\end{array}$ & $\{0,8.83,49.17,1650\}$ \\
\hline$H_{4}(\mathrm{IV})$ & Serious & To formulate precaution and warning measures & $\{0,199.38,641.67,30250\}$ \\
\hline$H_{5}(\mathrm{~V})$ & Intolerable & $\begin{array}{l}\text { To cease and initiate the contingency plan } \\
\text { immediately }\end{array}$ & $\{100,9762.5,31250,100000\}$ \\
\hline
\end{tabular}

Note*: For uniformity, the risk grades in Table 4 ae equivalent to what MoC (2007) regulates in Table 3

\subsection{Determination on the weight of the hazardous events}

Through the procedure of section 3.3, the risk level of an individual hazardous event could be received. Moreover, if we want to further obtain the overall risk level of the DFP, a procedure of multi-layer risk fusion should be conducted, which is from hazardous event level to hazard group level, and finally to the total object level (An et al., 2011). Given that the influence degree of each hazard to the overall risk level is different, the weighing factor is employed. The methods to determine the weighing factor are usually divided into three categories: subjective method, objective method, and hybrid method (Yang et al., 2017). As a kind of subjective method, the analytical hierarchy process (AHP) to obtain the influence of each factor is suitable for the scenarios of qualitative evaluation, and the result generated can reflect the subjective preference of the decision maker. Fuzzy-analytical hierarchy process (FAHP) is an important extension of the traditional AHP method (An et al., 2011; An et al., 2016), which uses a similar framework of AHP to conduct risk analysis but fuzzy ratios of relative importance replace crisp ratios to the existence of uncertainty in the risk assessment. An advantage of the FAHP is its flexibility of integrating with other techniques, for example, the integration with ER in risk analysis. There are six steps to calculate the weighing factors as described below (An et al., 2011).

Step1: To establish an estimation scheme

The same as the traditional AHP method, FAHP determines the weighing factors through pairwise comparison. The comparison is based on an estimation scheme, which lists the intensity of importance using qualitative descriptors. Each qualitative descriptor has a corresponding trapezoidal membership function that is employed to transfer expert judgments into a comparison 

analysis in DFP.

\begin{tabular}{lcc}
\hline Qualitative descriptors & Description & Trapezoidal fuzzy \\
& & numbers \\
\hline Equal importance & Two risk contributors contribute equally & $\{1,1,1,2\}$ \\
Week importance & contributor over another & $\{1,2,2,3\}$ \\
Between week and strong & When compromise is needed & \\
importance & Experience and judgment strongly favor one risk & \\
Strong importance & contributor over another & $\{2,3,4,5\}$ \\
Between strong and very & When compromise is needed & \\
strong importance & is of the highest possible order of affirmation & \\
Very strong importance & A risk contributor is favored very strongly over the other & $\{7,5,5,6\}$ \\
Absolute importance & The evidence favoring one risk contributor over another & $\{8,8,9\}$ \\
\hline
\end{tabular}
than $h_{2}$, a fuzzy number of $(4,5,5,6)$ is then assigned to $h_{1}$ based on the estimation scheme as shown in Table 5. Correspondingly, risk contributor $h_{2}$ has a fuzzy number of $(1 / 6,1 / 5,1 / 5,1 / 4)$. If there are $m$ risk contributors in the index system, a total of $(m(m-1) / 2)$ pairs needs to be compared.

Step 3: To aggregate the comparative results

Generally, multiple experts are involved in the risk assessment and their judgment may be different. Therefore, the comparative result from each individual expert should be aggregated into a synthetic result for each risk contributor. The process is the same as what has been described in Eq. (4) or Eq. (5). 
Suppose that $h_{1}, h_{2}, \ldots, h_{m}$ are risk factors in a hazard group, $A_{x, y}$ is the synthetic result representing the quantified judgment on $h_{x}$ comparing with $h_{y}$. The pairwise comparison between $h_{x}$ and $h_{y}$ in the hazard group thus yields a $m \times m$ matrix shown as:

$$
\begin{gathered}
M=\left[A_{x, y}\right]=\left[\begin{array}{cccc}
A_{1,1} & A_{1,2} & \cdots & A_{1, m} \\
A_{2,1} & A_{2,2} & \cdots & A_{2, m} \\
\vdots & \vdots & \ddots & \vdots \\
A_{m, 1} & A_{m, 2} & \cdots & A_{m, m}
\end{array}\right] \\
x, y=1,2, \cdots, m, A_{x, y}=\left\{a_{x, y}, b_{x, y}, c_{x, y}, d_{x, y}\right\}, A_{y, x}=\left\{1 / d_{x, y}, 1 / c_{x, y}, 1 / b_{x, y}, 1 / a_{x, y}\right\}
\end{gathered}
$$

Where $a_{x, y}, b_{x, y}, c_{x, y}$, and $d_{x, y}$ are the numbers of $A_{x, y}$.

Step 5: To calculate weighing factors

The weighing factors can be calculated by using geometric mean method (An et al., 2011; Kim \& Zuo, 2018; Liu et al., 2013). The geometric mean $\bar{A}_{x}$ of the $x$ th row in the comparison matrix is defined as:

$$
\bar{A}_{x}=\left\{\bar{a}_{x}, \bar{b}_{x}, \bar{c}_{x}, \bar{d}_{x}\right\}=\left\{\sqrt[m]{\prod_{y=1}^{m} a_{x, y}}, \sqrt[m]{\prod_{y=1}^{m} b_{x, y}}, \sqrt[m]{\prod_{y=1}^{m} c_{x, y}}, \sqrt[m]{\prod_{y=1}^{m} d_{x, y}}\right\}
$$

Then the weighing factor $F W_{x}$ of risk factor $h_{x}$ can be received by:

$$
F W_{x}=\left\{a_{x}, b_{x}, c_{x}, d_{x}\right\}=\left\{\frac{\bar{a}_{x}}{\sum_{x=1}^{m} \bar{d}_{x}}, \frac{\bar{b}_{x}}{\sum_{x=1}^{m} \bar{c}_{x}}, \frac{\bar{c}_{x}}{\sum_{x=1}^{m} \bar{b}_{x}}, \frac{\bar{d}_{x}}{\sum_{x=1}^{m} \bar{a}_{x}}\right\}
$$

\subsubsection{Step 6: Defuzzification and normalization}

Since the outputs generated in Step 5 are fuzzy numbers, defuzzification and normalization are conducted to convert fuzzy numbers into normalized crisp values as:

$$
W_{x}^{\prime}=\frac{a_{x}+b_{x}+c_{x}+d_{x}}{4}
$$

$$
W_{x}=\frac{W_{x}^{\prime}}{\sum_{x=1}^{m} W_{x}^{\prime}}
$$

\section{Assessment on overall risk level of DFP}



pieces of evidence contributed by the risk level of all hazardous events depicted in Fig. 3 to reflect the overall risk of DFP construction. In order to implement the FER, a belief structure to represent the risk level of hazardous events should be realized firstly. of discernment associated with the risk grade shown in Table 4 is defined as $H=\left\{H_{n}, n=1,2, \ldots, 5\right\}$.

There are four steps to convert $R_{j}$ in the form of trapezoidal fuzzy number into the belief structure. Step 1: To plot out the curve of membership function according to Table 4.

Fig.4 below portraits the trapezoidal curves of membership function with respect to different risk grades of DFP $\left(H_{n}, n=1,2, \ldots, 5\right)$. as shown in Fig.5.

Step 3: To calculate the extent with respect to $R_{j}$ contributing to $H_{n}(n=1,2, \cdots, 5)$. respectively.

Suppose the intersection set formed by $R_{j}$ and $H_{n}$ is denoted by $S_{n}^{j}$, meanwhile, the area surrounded by both $H_{n}$ and the coordinate axis is represented by $S_{n}$, then calculate the extent with respect to $R_{j}$ contributing to $H_{n}$, which is defined as ratio of $S_{n}^{j}$ to $S_{n}$. According to Fig.5, it can be worked out $\quad$ that $S_{n}^{j}=\{0.50,0.47,0.03,1.40 E-3,0\}$ and $S_{n}=\{1.45,21.99,845.17,15346.15$, $60693.75\}$, then the results of $S_{n}^{j}$ to $S_{n}$ are obtained as $3.44 E-1,2.11 E-2,3.55 E-5,9.12 E-8$ and 0 Step 4: To work out the belief structure. Normalize the results obtained in Step 3 to receive the degree of belief $\beta_{n, j}$ 
$299 S\left(R_{j}\right)=\left\{\left(H_{n}, \beta_{n, j}\right), n=1,2, \ldots, 5\right\}$ could be obtained. Still think $R_{j}$ in Fig.5 as an example, the belief structure of $R_{j}$ is shown as follow:

$$
S\left(R_{j}\right)=\left\{\left(H_{1}, 0.94\right),\left(H_{2}, 0.06\right),\left(H_{3}, 9.72 E-5\right),\left(H_{4}, 2.50 E-7\right),\left(H_{5}, 0\right)\right\}
$$

\subsection{Fusion of risk based on the FER algorithm}

The principle of DFP risk assessment based on FER is that the risk level of each hazardous event provides evidence supporting that the overall risk of DFP reaches to a certain level. Based on this, the overall risk level of DFP could be obtained through evidential fusion. In general, given that the weighing factors and belief structures of the hazardous events are available, the basic probability mass $m_{j}\left\{H_{n}\right\}$ and the unassigned degree of belief $m_{j}\{H\}$ on hazardous event $e_{j}$ could be drawn out by the follow equations:

$$
\begin{aligned}
& m_{j}\left\{H_{n}\right\}=\omega_{j} \beta_{n, j} \\
& m_{j}\{H\}=1-\sum_{n=1}^{5} m_{j}\left\{H_{n}\right\}
\end{aligned}
$$

Furthermore, $m_{j}\{H\}$ could be divided into two parts, i.e., $\bar{m}_{j}\{H\}$ and $\tilde{m}_{j}\{H\}$. Where $\bar{m}_{j}\{H\}$ is caused by the relative importance of the attribute $e_{j}$ and $\tilde{m}_{j}\{H\}$ by the incompleteness of the assessment on $e_{j}$, denoted by the following equations:

$$
\begin{gathered}
\bar{m}_{j}\{H\}=1-\omega_{j} \\
\tilde{m}_{j}\{H\}=\omega_{j}\left(1-\sum_{n=1}^{5} \beta_{n, j}\right) \\
m_{j}\{H\}=\bar{m}_{j}\{H\}+\tilde{m}_{j}\{H\}
\end{gathered}
$$

After that, the FER algorithm is adopted to acquire the aggregated value of the probability mass $m_{1-\tilde{L}}\left\{H_{n}\right\}, m_{1-\tilde{L}}\left\{\bar{H}_{n,(n+1)}\right\}$, and $\bar{m}_{1-\tilde{L}}\{H\}$ as follows:

$$
m_{1-\tilde{L}}\left\{H_{n}\right\}=k\left\{\prod_{j=1}^{\tilde{L}}\left[m_{j}\left\{H_{n}\right\}+m_{j}\{H\}\right]-\prod_{j=1}^{\tilde{L}} m_{j}\{H\}\right\}, \quad n=1,2, \ldots, 5
$$




$$
\begin{aligned}
& m_{1-\tilde{L}}\left\{\bar{H}_{n,(n+1)}\right\}= k \mu_{H_{n,(n+1)} \max }\left\{\prod_{j=1}^{\tilde{L}}\left[m_{j}\left\{H_{n}\right\}+m_{j}\left\{H_{n+1}\right\}+m_{j}\{H\}\right]-\prod_{j=1}^{\tilde{L}}\left[m_{j}\left\{H_{n}\right\}+m_{j}\{H\}\right]\right. \\
&\left.-\prod_{j=1}^{\tilde{L}}\left[m_{j}\left\{H_{n+1}\right\}+m_{j}\{H\}\right]+\prod_{j=1}^{\tilde{L}} m_{j}\{H\}\right\}, n=1,2, \ldots, 4 \\
& \bar{m}_{1-\tilde{L}}\{H\}=k\left\{\prod_{j=1}^{\tilde{L}} \bar{m}_{j}\{H\}\right\} \\
& k=\left\{\sum_{n=1}^{4}\left(1-\mu_{H_{n,(n+1)}}^{\max }\right)\left(\prod_{j=1}^{\tilde{L}}\left[m_{j}\left\{H_{n}\right\}+m_{j}\{H\}\right]-\prod_{j=1}^{\tilde{L}} m_{j}\{H\}\right)\right. \\
&+\sum_{n=1}^{4} \mu_{H_{n,(n+1)}}^{\max }\left(\prod_{j=1}^{\tilde{L}}\left[m_{j}\left\{H_{n}\right\}+m_{j}\left\{H_{n+1}\right\}+m_{j}\{H\}\right]-\prod_{j=1}^{\tilde{L}}\left[m_{j}\left\{H_{n+1}\right\}+m_{j}\{H\}\right]\right) \\
&\left.+\prod_{j=1}^{\tilde{L}}\left[m_{j}\left\{H_{5}\right\}+m_{j}\{H\}\right]\right\}
\end{aligned}
$$

While $H_{n,(n+1)}$ is the intersection of two adjacent assessment grades $H_{n}$ and $H_{n+1}, \quad \bar{H}_{n,(n+1)}$ is a normalized fuzzy subset for the fuzzy intersection subset $H_{n,(n+1)}$ whose maximum degree of membership is represented by $\mu_{H_{n,(n+1)}}^{\max }$ (Yang et al., 2006).

However, as Fig. 4 illustrates, the total number of intersections is more than the scenario in traditional fuzzy set, due to the fact that intersections exist not only between two adjacent fuzzy evaluation grades, but also the non-adjacent two fuzzy evaluation grades. For example, there exists intersection between $H_{1}$ and $H_{3}$. Therefore, the expression of $m_{1-\tilde{L}}\left\{\bar{H}_{n,(n+1)}\right\}$ should be changed to $m_{1-\tilde{L}}\left\{\bar{H}_{n,(n+t)}\right\}$, where $1 \leq t \leq 4$ and $n+t \leq 5$. Accordingly, the varied equation is described as follows: 
After the risk levels (evidences) of $\tilde{L}$ hazardous events have been assembled, the aggregated degree of belief $\beta_{n}$ and $\beta_{n,(n+t)}$ could be calculated respectively by:

Where $\beta_{n,(n+t)}$ denotes the degree of belief to which the overall risk level of DFP lies when the intersection of grade $H_{n}$ and $H_{n+t}$ exists. However, no corresponding evaluation grade as $H_{n,(n+t)}$ appears in the fuzzy evaluation grades which is also referred to the frame of discernment in Yang circumstance of the intersections of grade $H_{n}$ and $H_{n+t}$, there are two situations to redistribute $\beta_{n,(n+t)}$ :

First scenario: The maximum membership degree of the intersection of two fuzzy evaluation grades is lower than one, which is shown as Fig. 6a.

351 Suppose that $\bar{H}_{n,(n+t)}$ is the normalized result of $H_{n,(n+t)}$, and $\bar{H}_{n,(n+t)}$ intersects $H_{n}$ with an area of $\left(S_{n}+S_{n,(n+t)}\right)$ and $H_{n+t}$ with an area of $\left(S_{n+t}+S_{n,(n+t)}\right)$, where $S_{n,(n+t)}$ is the common area among $\bar{H}_{n,(n+t)}$, $H_{n}$, and $H_{n+t}$. The minimum distance between the peaks of $\bar{H}_{n,(n+t)}$ and $H_{n}$ is denoted as $d_{n}$ and that between the peaks of $\bar{H}_{n,(n+t)}$ and $H_{n+t}$ as $d_{n+t}$, then $\beta_{n,(n+t)}$ can be redistributed by Eq. (25) and Eq. (26) (Yang et al., 2006):

$$
\beta_{n+t}^{n,(n+t)}=\frac{\mathrm{AF}_{n+t}^{n,(n+t)} \cdot \mathrm{S}_{n,(n+t)}+S_{n+t}}{S_{n}+\mathrm{S}_{n,(n+t)}+S_{n+t}} \cdot \beta_{n,(n+t)}
$$




$$
\mathrm{AF}_{n}^{n,(n+t)}=\frac{1}{2}\left[\left(1-\frac{d_{n}}{d_{n}+d_{n+t}}\right)+\frac{S_{n}}{S_{n}+S_{n+t}}\right]
$$

$$
\mathrm{AF}_{n+t}^{n,(n+t)}=\frac{1}{2}\left[\left(1-\frac{d_{n+t}}{d_{n}+d_{n+t}}\right)+\frac{S_{n+t}}{S_{n}+S_{n+t}}\right]
$$

Second scenario: The maximum membership degree of the intersection of two fuzzy evaluation grades is equal to one, which is shown as Fig. $6 \mathrm{~b}$.

(26) will be changed as follows:

$$
\beta_{n}^{n,(n+t)}=A F_{n}^{n,(n+t)} \cdot \beta_{n,(n+t)}
$$

$$
\beta_{n+t}^{n,(n+t)}=A F_{n+t}^{n,(n+t)} \cdot \beta_{n,(n+t)}
$$

Suppose $S_{n}^{\prime}$ refers to the remaining area of $H_{n}$ deducted by $S_{n,(n+t)}$ and $S_{n+t}^{\prime}$ refers to the remaining can be defined by:

After all values of $\beta_{n,(n+t)}(n=1,2, \ldots, 4, t=1,2, \ldots, 4$, and $n+t \leq 5)$ have be redistributed, the overall risk level of the DFP in belief structure could be depicted as: $S\left(R_{\text {overall }}\right)=\left\{\left(H_{n}, \beta_{n}\right), n=1,2, \ldots, 5\right\}$. It is worth noting that the result of $\beta_{n}$ is the combination of two parts: one comes from aggregated result generated by Eq. (23), and the other one from the redistribution of $\beta_{n,(n+t)}$.

\section{Case Study}

\subsection{Project Overview}

$$
\mathrm{AF}_{n}^{n,(n+t)}=1-\frac{S_{n}^{\prime}+S_{n,(n+t)}}{S_{n}^{\prime}+2 S_{n,(n+t)}+S_{n+t}^{\prime}}
$$

$$
\mathrm{AF}_{n+t}^{n,(n+t)}=1-\frac{S_{n,(n+t)}+S_{n+t}^{\prime}}{S_{n}^{\prime}+2 S_{n,(n+t)}+S_{n+t}^{\prime}}
$$

The underground traffic project of Zhengzhou Comprehensive Transportation Hub is located on the east side of Zhengzhou East Station, China. The construction area in total is $113,367.8 \mathrm{~m}^{2}$, which 


\begin{tabular}{cccc}
\hline Experts & Years of experience & $R_{i}$ & $E_{i}$ \\
\hline $\mathrm{A}$ & 15 & 3.29 & 0.14 \\
$\mathrm{~B}$ & 20 & 5.19 & 0.24 \\
$\mathrm{C}$ & 18 & 4.43 & 0.19 \\
$\mathrm{D}$ & 30 & 9 & 0.39 \\
$\mathrm{E}$ & 9 & 1 & 0.04 \\
\hline
\end{tabular}

is an underground three-story reinforced concrete structure. The DFP excavation depth is $20 \mathrm{~m}$ down to the underground and the DFP construction is divided by the tunnel of Metro Line One into two areas: the south half and the north half, which are linked by three connecting passages. The two parts of the DFP is surrounded by underground continuous wall. Concrete cast-in-place pile is used in three areas, i.e. around the area used Bottom-Up Method, the area used Top-Down Method nearby both sides of the tunnel and the area on both sides of the three connecting passages. The minimum net distance between the bottom of the connecting passage and the top of the tunnel structure is only four meters. Therefore, the protection of the interval tunnel for normal operation of the metro line is the key part of this DFP construction project. The construction area of the foundation pit is shown in Fig.7.

\subsection{Data collection}

Five experts (assessors), A, B, C, D, and E, were invited to assess the DFP construction risks. Expert index $E I_{\tilde{i}}$ calculated by Eq. (2) are shown in Table 6. In terms of Definition 1 in the section 3.1 of this paper, the relevant importance $\left(R I_{\tilde{i}}\right)$ of expert $\mathrm{D}$ valued as 9 due to the fact that he has got the richest working experience. Conversely, expert $\mathrm{E}$ received the minimum value $R I_{\tilde{i}}$ as 1 because of his weakest experience comparatively. The relevant importance $\left(R I_{\tilde{i}}\right)$ of the remaining three experts are obtained by the interpolation method (An et al., 2011).

Table 6 Expert index $E I_{i}$ of five experts

Brainstorming session was introduced among the five experts to enumerate all the hazardous events related to the DFP construction. Risks in relation to nineteen hazardous events, nine hazard groups, and three sub-objects were identified and defined as follows:

(1) The first sub-object risk identified is the technical one which includes four hazard groups 
i.e. earth excavation, dewatering, excavation bracing, and structural works. Pit landslide and upheaval in the bottom are thought to be two critical hazards in earth excavation. Both rush of confined water and leakage of foundation pit are two common hazards in the process of dewatering. Destabilization of support and excessive deformation of enclosure are regarded as two key causes of excavation bracing failure. There are three representative hazards, according to the experts, need to be cautioned in structural works i.e. concrete cracking, template failure, and upward displacement of structure.

(2) The second sub-object risk is the management one which consists of three hazard groups: safety awareness, safety regulations, and safety facilities management. Each of hazard

Table 7 Weighing factors of risk contributors

\begin{tabular}{cccc}
\hline Risk contributors at sub- & Risk contributors at hazard & Risk contributors at hazardous & Global \\
object level (local weights) & group level (local weights) & event level (local weights) & weights \\
\hline Technical risk $(0.2)$ & Earth excavation $(0.18)$ & $\mathrm{e}_{1}(0.54)$ & 0.019 \\
& & $\mathrm{e}_{2}(0.46)$ & 0.017
\end{tabular}




\begin{tabular}{|c|c|c|c|}
\hline & Dewatering (0.24) & $e_{3}(0.68)$ & 0.033 \\
\hline & & $\mathrm{e}_{4}(0.32)$ & 0.015 \\
\hline & Excavation bracing $(0.37)$ & $\mathrm{e}_{5}(0.52)$ & 0.038 \\
\hline & & $\mathrm{e}_{6}(0.48)$ & 0.035 \\
\hline & Structural works $(0.21)$ & $\mathrm{e}_{7}(0.22)$ & 0.009 \\
\hline & & $\mathrm{e}_{8}(0.17)$ & 0.007 \\
\hline & & $e_{9}(0.61)$ & 0.026 \\
\hline \multirow[t]{6}{*}{ Management risk $(0.07)$} & Safety awareness $(0.44)$ & $\mathrm{e}_{10}(0.35)$ & 0.012 \\
\hline & & $\mathrm{e}_{11}(0.65)$ & 0.02 \\
\hline & Safety regulations $(0.35)$ & $\mathrm{e}_{12}(0.7)$ & 0.017 \\
\hline & & $\mathrm{e}_{13}(0.3)$ & 0.007 \\
\hline & Safety facilities $(0.21)$ & $\mathrm{e}_{14}(0.53)$ & 0.008 \\
\hline & & $\mathrm{e}_{15}(0.47)$ & 0.007 \\
\hline \multirow[t]{4}{*}{ Environmental risk $(0.73)$} & Differential settlement & $\mathrm{e}_{16}(0.92)$ & 0.484 \\
\hline & $(0.72)$ & $\mathrm{e}_{17}(0.08)$ & 0.042 \\
\hline & Damage of third-party & $\mathrm{e}_{18}(0.66)$ & 0.135 \\
\hline & $(0.28)$ & $\mathrm{e}_{19}(0.34)$ & 0.069 \\
\hline
\end{tabular}

430 five experts, and then the combined results were received by Eq. (4) and Eq. (5). On the basis of the 431 combined results, Eq. (3) was used to calculate the risk level of each hazardous event (shown in 432 Table 8).

Table 8 The occurrence likelihood, consequence severity and risk level of all hazardous events

\begin{tabular}{cccc}
\hline Hazardous & Occurrence likelihood ( & Consequence severity $(S$ & Risk level $(R)$ \\
events & $L)$ & $\{0,0,250,500\}$ & $\{0,0,110.5,360.5\}$ \\
\hline $\mathrm{e}_{1}$ & $\{4.42 \mathrm{E}-2,2.43 \mathrm{E}-1$, & & $\{0,0,2.5,27.5\}$ \\
& $4.42 \mathrm{E}-1,7.21 \mathrm{E}-1\}$ & $\{0,0,250,500\}$ & \\
$\mathrm{e}_{2}$ & $2,0 \mathrm{E}-3,5.5 \mathrm{E}-3,1.0 \mathrm{E}-$ & & $\{9.7,159.5,484,4026\}$ \\
$\mathrm{e}_{3}$ & $\{1.0 \mathrm{E}-2,5.5 \mathrm{E}-2,1.0 \mathrm{E}-$ & $\{970,2900,4840,7320\}$ &
\end{tabular}




\begin{tabular}{|c|c|c|c|}
\hline $\mathrm{e}_{4}$ & $\{1.0 \mathrm{E}-1,5.5 \mathrm{E}-1,1.0,1.0\}$ & $\{0,0,250,500\}$ & $\{0,0,250,500\}$ \\
\hline $\mathrm{e}_{5}$ & $\begin{array}{c}\{1.0 \mathrm{E}-3,5.5 \mathrm{E}-3,1.0 \mathrm{E}- \\
2,5.5 \mathrm{E}-2\}\end{array}$ & $\{250,500,1000,3000\}$ & $\{0.25,2.75,10,165\}$ \\
\hline $\mathrm{e}_{6}$ & $\begin{array}{c}\{1.0 \mathrm{E}-2,5.5 \mathrm{E}-2,1.0 \mathrm{E}- \\
1,5.5 \mathrm{E}-1\}\end{array}$ & $\{240,480,970,2900\}$ & $\{2.4,26.4,97,1595\}$ \\
\hline $\mathrm{e}_{7}$ & $\begin{array}{l}\{8.29 \mathrm{E}-2,4.56 \mathrm{E}-1, \\
8.29 \mathrm{E}-1,9.15 \mathrm{E}-1\}\end{array}$ & $\{0,0,250,500\}$ & $\{0,0,207.25,457.25\}$ \\
\hline $\mathrm{e}_{8}$ & $\begin{array}{c}\{1.0 \mathrm{E}-3,5.5 \mathrm{E}-3,1.0 \mathrm{E}- \\
2,5.5 \mathrm{E}-2\}\end{array}$ & $\{0,0,250,500\}$ & $\{0,0,2.5,27.5\}$ \\
\hline $\mathrm{e}_{9}$ & $\begin{array}{c}\{5 \mathrm{E}-5,1.0 \mathrm{E}-4,1.0 \mathrm{E}- \\
3,5.5 \mathrm{E}-3\}\end{array}$ & $\{1000,3000,5000,7500\}$ & $\{0.05,0.3,5,41.25\}$ \\
\hline $\mathrm{e}_{10}$ & $\begin{array}{l}\{9.64 \mathrm{E}-2,5.3 \mathrm{E}-1, \\
9.64 \mathrm{E}-1,9.82 \mathrm{E}-1\}\end{array}$ & $\{0,0,250,500\}$ & $\{0,0,241,491\}$ \\
\hline$e_{11}$ & $\begin{array}{l}\{6.13 \mathrm{E}-2,3.37 \mathrm{E}-1, \\
6.13 \mathrm{E}-1,8.07 \mathrm{E}-1\}\end{array}$ & $\{0,0,250,500\}$ & $\{0,0,153.25,403.25\}$ \\
\hline$e_{12}$ & $\begin{array}{c}\{5.0 \mathrm{E}-5,1.0 \mathrm{E}-4,1.0 \mathrm{E}- \\
3,5.5 \mathrm{E}-3\}\end{array}$ & $\{0,0,250,500\}$ & $\{0,0,0.25,2.75\}$ \\
\hline$e_{13}$ & $\begin{array}{l}\{6.13 \mathrm{E}-3,3.37 \mathrm{E}-2, \\
6.13 \mathrm{E}-2,3.37 \mathrm{E}-1\}\end{array}$ & $\{0,0,250,500\}$ & $\{0,0,15.33,168.58\}$ \\
\hline$e_{14}$ & $\begin{array}{l}\{7.84 \mathrm{E}-3,4.31 \mathrm{E}-2, \\
7.84 \mathrm{E}-2,4.31 \mathrm{E}-1\}\end{array}$ & $\{0,0,250,500\}$ & $\{0,0,19.6,215.6\}$ \\
\hline$e_{15}$ & $\begin{array}{l}\{8.29 \mathrm{E}-3,4.56 \mathrm{E}-2, \\
8.29 \mathrm{E}-2,4.56 \mathrm{E}-1\}\end{array}$ & $\{0,0,250,500\}$ & $\{0,0,20.73,227.98\}$ \\
\hline$e_{16}$ & $\begin{array}{l}\{1.99 \mathrm{E}-3,1.09 \mathrm{E}-2, \\
2.01 \mathrm{E}-2,1.1 \mathrm{E}-1\}\end{array}$ & $\{6200,18900,31600,65800\}$ & $\{12.36,206.35,634.53,7266.95\}$ \\
\hline$e_{17}$ & $\{1.0 \mathrm{E}-1,5.5 \mathrm{E}-1,1.0,1.0\}$ & $\{0,0,250,500\}$ & $\{0,0,250,500\}$ \\
\hline$e_{18}$ & $\begin{array}{l}\{4.21 \mathrm{E}-4,2.21 \mathrm{E}-3, \\
4.51 \mathrm{E}-3,2.48 \mathrm{E}-2\}\end{array}$ & $\{82.5,165,497.5,1325\}$ & $\{0.03,0.36,2.24,32.87\}$ \\
\hline $\mathrm{e}_{19}$ & $\begin{array}{c}\{1.0 \mathrm{E}-3,5.5 \mathrm{E}-3,1.0 \mathrm{E}- \\
2,5.5 \mathrm{E}-2\}\end{array}$ & $\{0,0,250,500\}$ & $\{0,0,2.5,27.5\}$ \\
\hline
\end{tabular}

435 Firstly, all of the risk levels in Table 8 were converted into belief structures using the method 436 described in Section 4.1, the results obtained were depicted in Table 9. 


\begin{tabular}{|c|c|c|c|c|c|}
\hline \multirow{2}{*}{ Hazardous events } & \multicolumn{5}{|c|}{ Belief structure } \\
\hline & $\left\{H_{1}\right\}$ & $\left\{H_{2}\right\}$ & $\left\{H_{3}\right\}$ & $\left\{H_{4}\right\}$ & $\left\{H_{5}\right\}$ \\
\hline $\mathrm{e}_{1}$ & 0.466 & 0.466 & 0.064 & 0.004 & 0.000 \\
\hline $\mathrm{e}_{2}$ & 0.590 & 0.402 & 0.008 & 0.000 & 0.000 \\
\hline$e_{3}$ & 0.000 & 0.022 & 0.840 & 0.128 & 0.009 \\
\hline $\mathrm{e}_{4}$ & 0.429 & 0.429 & 0.135 & 0.008 & 0.000 \\
\hline $\mathrm{e}_{5}$ & 0.290 & 0.641 & 0.067 & 0.002 & 0.000 \\
\hline $\mathrm{e}_{6}$ & 0.001 & 0.349 & 0.617 & 0.031 & 0.001 \\
\hline $\mathrm{e}_{7}$ & 0.418 & 0.418 & 0.158 & 0.006 & 0.000 \\
\hline$e_{8}$ & 0.590 & 0.402 & 0.008 & 0.000 & 0.000 \\
\hline $\mathrm{e}_{9}$ & 0.465 & 0.523 & 0.012 & 0.000 & 0.000 \\
\hline $\mathrm{e}_{10}$ & 0.412 & 0.412 & 0.169 & 0.007 & 0.000 \\
\hline $\mathrm{e}_{11}$ & 0.429 & 0.429 & 0.137 & 0.005 & 0.000 \\
\hline $\mathrm{e}_{12}$ & 0.937 & 0.062 & 0.000 & 0.000 & 0.000 \\
\hline $\mathrm{e}_{13}$ & 0.475 & 0.475 & 0.049 & 0.001 & 0.000 \\
\hline $\mathrm{e}_{14}$ & 0.468 & 0.468 & 0.063 & 0.002 & 0.000 \\
\hline $\mathrm{e}_{15}$ & 0.466 & 0.466 & 0.066 & 0.002 & 0.000 \\
\hline $\mathrm{e}_{16}$ & 0.000 & 0.066 & 0.712 & 0.202 & 0.021 \\
\hline $\mathrm{e}_{17}$ & 0.429 & 0.429 & 0.135 & 0.008 & 0.000 \\
\hline $\mathrm{e}_{18}$ & 0.519 & 0.472 & 0.010 & 0.000 & 0.000 \\
\hline $\mathrm{e}_{19}$ & 0.590 & 0.402 & 0.008 & 0.000 & 0.000 \\
\hline
\end{tabular}


be calculated by Eq. (12) and Eq. (13). The risk level of each hazardous event provided evidence supporting that the overall risk of DFP reaches to a certain level; then, the aggregated probability $\operatorname{masses} m_{1-\tilde{L}}\left\{H_{n}\right\}$ and $m_{1-\tilde{L}}\left\{\bar{H}_{n,(n+t)}\right\}(\tilde{L}=19, n=1,2, \ldots, 5, t=1,2, \ldots, 4$, and $n+t \leq 5)$ could be obtained by Eq. (14) Eq. (22), which were shown as Table 10.

Table 10 Aggregated probability masses of risk assessment

\begin{tabular}{cccccc}
\hline$n$ & $m\left\{H_{n}\right\}$ & $m\left\{\bar{H}_{1, n}\right\}$ & $m\left\{\bar{H}_{2, n}\right\}$ & $m\left\{\bar{H}_{3, n}\right\}$ & $m\left\{\bar{H}_{4, n}\right\}$ \\
\hline 1 & 0.091 & & & & \\
2 & 0.112 & 0.026 & & & \\
3 & 0.270 & 0.017 & 0.061 & & \\
4 & 0.067 & 0.000 & 0.003 & 0.006 & 0 \\
5 & 0.007 & 0 & 0 & 0 & \\
\hline & & $k=1.123 ;$ & $m\{H\}=0.340 ;$ & $\bar{m}\{H\}=0.340$ &
\end{tabular}

Eq. (23) and Eq. (24) were used to generate the aggregated degree of belief $\beta_{n}$ and $\beta_{n,(n+t)}$; and then $\beta_{n,(n+t)}$ was redistributed by Eq. (25) $\sim$ Eq. (32). Ultimately, the belief structure of overall risk of the foundation pit was received as Table 11.

Table 11 The belief structure of overall risk of the foundation pit

\begin{tabular}{cccccc}
\hline & $\left\{H_{1}\right\}$ & $\left\{H_{2}\right\}$ & $\left\{H_{3}\right\}$ & $\left\{H_{4}\right\}$ & $\left\{H_{5}\right\}$ \\
\hline$\beta_{n}$ & 0.197 & 0.193 & 0.489 & 0.110 & 0.010
\end{tabular}

As demonstrated in Table 11, the most probability of the overall DFP risk was valued as 0.489 , which falls into the risk grade III. Since risks under grade III are illustrated as Need-Consider in

Table 4, the control strategy adopted in present was to rule with preventive and monitoring measures.

\section{Discussion}

$452 \quad 6.1$ Sensitivity analysis

453 Through the above processes, the assessment of overall risk level of the DFP construction could 454 be arrived, but the degree of each potential hazard that contributes to the overall risk level has not 455 been revealed. In other words, which hazardous event should be paid more attention in risk control 456 is not explicit yet. Therefore, the sensitivity analysis is employed to examine the sensitivity of individual hazards. 
Suppose that the numerical utility values of $\beta_{n}(n=1,2, \ldots, 5)$ are linearly assigned as follows:

$$
U\left(\beta_{1}\right)=0, U\left(\beta_{2}\right)=0.3, U\left(\beta_{3}\right)=0.5, U\left(\beta_{4}\right)=0.7, U\left(\beta_{5}\right)=1
$$

Then, the overall risk score of the DFP could be calculated by:

$$
\operatorname{Score}(R)=\sum_{n=1}^{5} \beta_{n} \times U\left(\beta_{n}\right)
$$

Subsequently, the belief structure of each hazard is varied in turn to the same extent to observe the impact on the overall risk score of the DFP. Intuitively, the greater the impact generates, the more sensitive the hazard is. For example, with respect to each hazard, the degree of belief that belongs to ' $H_{1}$ 'rises by 0.05 , correspondingly, the degree of belief that belongs to ' $H_{5}$ ' decreases by 0.05 . If the degree of belief attached to ' $H_{5}$ ' is less than 0.05 , then the scant degree of belief [ $0.05-\beta_{5}$ ] can be deducted from ' $H_{4}$ ', this process continues until the 0.05 of degree of belief is consumed. The impact of the above operation on the overall risk score of the DFP is shown in Fig.9. for any hazard, may lead to a decrease or an increase of the overall risk score correspondingly. operation of take absolute value. displayed in Table 12.

\begin{tabular}{|c|c|c|c|c|}
\hline Hazardous & $V D_{j}$ generated as ' $\mathrm{H}_{1}$ ' is & $V D_{j}$ generated as ' $\mathrm{H}_{1}$ ' is & Average of & \\
\hline events & added by 0.05 in $e_{j}$ & deducted by 0.05 in $e_{j}$ & $V D_{j}$ & Капкпा \\
\hline
\end{tabular}




\begin{tabular}{|c|c|c|c|c|}
\hline $\mathrm{e}_{1}$ & $4.955^{*}$ & 7.134 & 6.044 & 10 \\
\hline $\mathrm{e}_{2}$ & 2.680 & 6.373 & 4.526 & 12 \\
\hline$e_{3}$ & 11.563 & 5.852 & 8.708 & 7 \\
\hline $\mathrm{e}_{4}$ & 3.979 & 5.618 & 4.798 & 11 \\
\hline $\mathrm{e}_{5}$ & 9.792 & 14.436 & 12.114 & 5 \\
\hline $\mathrm{e}_{6}$ & 10.986 & 8.561 & 9.773 & 6 \\
\hline $\mathrm{e}_{7}$ & 2.367 & 3.359 & 2.863 & 15 \\
\hline$e_{8}$ & 1.096 & 2.610 & 1.853 & 19 \\
\hline $\mathrm{e}_{9}$ & 4.340 & 9.798 & 7.069 & 8 \\
\hline$e_{10}$ & 3.181 & 4.487 & 3.834 & 14 \\
\hline$e_{11}$ & 5.243 & 7.515 & 6.379 & 9 \\
\hline$e_{12}$ & 2.381 & 6.370 & 4.375 & 13 \\
\hline$e_{13}$ & 1.782 & 2.610 & 2.196 & 18 \\
\hline $\mathrm{e}_{14}$ & 2.038 & 2.984 & 2.511 & 16 \\
\hline$e_{15}$ & 1.786 & 2.610 & 2.198 & 17 \\
\hline $\mathbf{e}_{16}$ & 254.089 & 206.672 & 230.381 & 1 \\
\hline$e_{17}$ & 11.288 & 15.992 & 13.640 & 4 \\
\hline$e_{18}$ & 23.170 & 54.384 & 38.777 & 2 \\
\hline$e_{19}$ & 11.171 & 26.654 & 18.912 & 3 \\
\hline
\end{tabular}

482 It can be drawn out from Table 12 that, the biggest variation in overall risk score results from the 483 variation of belief structure in relation to $e_{16}$, which also occupies biggest global weight in Table 7 .

484 When comparing Table 12 with Table 7, it could be found that the bigger the global weight of the 
hazard is, the greater the impact on the overall risk score happens, which matches well with people's intuition. That is, the hazardous event with bigger global weight denotes more sensitive factor contributing to the overall risk level of the DFP construction, which deserves to paid more attention in risk control operations.

\subsection{Comparison with previous studies}

Comparison with the previous methods, for example, the FER method by Mokhtari et al. (2012)

491 and the fuzzy reasoning approach by An et al. (2011), is presented to validate the effectiveness of 492 the method in this paper. It is worth mentioning that the membership function of each risk grade using in fuzzy reasoning approach is not grounded on the product of occurrence likelihood multiplying consequence severity, instead, it depends on the domain knowledge of risk experts involved. So, by learning lessons from An et al. (2011) and Mokhtari et al. (2012), a new arrangement of the membership function in relation to five-grade risk scale is drawn ( as shown in Table 13).

Table 13 The five-grade risk levels and the corresponding membership functions

\begin{tabular}{ccc}
\hline Risk grade & Linguistic description & Membership function \\
\hline$H_{1}$ & Negligible & $\{0,0,1,2\}$ \\
$H_{2}$ & Slight & $\{1,2,3,4\}$ \\
$H_{3}$ & Need-Consider & $\{3,4,5,6\}$ \\
$H_{4}$ & Serious & $\{5,6,7,8\}$ \\
$H_{5}$ & Intolerable & $\{7,8,9,9\}$
\end{tabular}
in Table 14.

Table 14 The comparison of results obtained by using three methods respectively

\begin{tabular}{cccccc}
\hline \multirow{2}{*}{ Adopted method } & \multicolumn{5}{c}{ The obtained results } \\
\cline { 2 - 6 } & $\left\{H_{1}\right\}$ & $\left\{H_{2}\right\}$ & $\left\{H_{3}\right\}$ & $\left\{H_{4}\right\}$ & $\left\{H_{5}\right\}$ \\
\hline FER used in this paper & 0.197 & 0.193 & 0.489 & 0.110 & 0.010 \\
FER used in Mokhtari et al. (2012) & 0.103 & 0.139 & 0.351 & 0.310 & 0.097
\end{tabular}



three methods, but with different degree of belief. The reason accounting for the different degree of belief could be elaborated as two-fold: (1). The fuzzy reasoning approach is grounded on Mamdani method (An et al., 2011; Bandeira et al., 2018; Markowski \& Mannan, 2008) which determines the rule to be involved in reasoning through using series of Minimal and Maximal Operators. In other words, the values between the minimal and maximal ones are abandoned in the process of reasoning, which enables the evaluated result to be either a singular number, i.e., the degree of belief equals to one just as the status shown in Table 14, or even numbers with the degree of beliefs less than one respectively but equal to one in total when the aggregated risk score locates in the intersection of two adjacent fuzzy risk grades. (2). Two distinct ways in developing belief structure may lead to the difference between the methods proposed in this paper and Mokhtari et al. (2012), although FER is employed in both methods. In this paper, the area of intersection between input fuzzy set and fuzzy risk grade is adopted to determine the degree of membership which is further converted into belief structure. However, it is the maximum ordinate value of the intersecting point, but not the area of intersection, that is used as the basis for developing belief structure in Mokhtari et al. (2012). belief structure. Just as Fig. 10 indicates that the area of intersection between input fuzzy set $R_{j}$ and fuzzy risk grade $H_{n}$ increases gradually as the location of input fuzzy set $R_{j}$ changing from Fig. 10(a) i.e. equals to one, which denotes that the degree of membership remains the same as the location of fuzzy set $R_{j}$ changing.

\section{Conclusion}

Risk assessment is an essential element in ensuring the effective construction management of DFP. Based on the FER approach, a new method is proposed in this paper to assess the overall risk level of DFP construction. In this method, the occurrence likelihood, consequence severity, and risk grade are firstly classified by trapezoidal fuzzy numbers according to the regulations defined in MoC (2007). Then, an approach of data acquisition taking into account the impacting factor from 
the risk assessors' expertise is adopted to obtain more reliable results of risk assessment on the potentially happened hazards. Applying FER algorithms, the risk level of each possible hazardous event is aggregated into the overall risk of DFP construction. A case study on DFP risk assessment of underground traffic project of Zhengzhou comprehensive transportation hub, China, is introduced in this paper to verify the application of the proposed method.

Comparing with the previous methods, the advantages of the proposed method can be summarized as: (1). the dilemma that different combinations of likelihood and consequence assigned with identical risks in traditional risk matrices has been overcome through depicting the specific risk grade with a sole trapezoidal fuzzy number; (2). the method which engage the impacting factors of expertise in the process of data acquisition, enables the results of risk assessment on the potentially happened hazards more objective; (3). the proposed method makes an attempt on implementing FER under the scenario that more than two continuous fuzzy evaluation grades intersect rather than only two adjacent grades; (4). the result of risk assessment obtained by the new method may be more reasonable, owing to its coincidence with the fact that the bigger the global weight of the hazard is, the greater the impact on the overall risk score is generated.

The successful application of the proposed method in this study indicates its practicality, whereas there are two limitations which deserve further consideration. First, the amount of computation is tremendous in this method, which may be a major obstacle for its universal application in practice. It is advised here to develop a computerized application to reduce the workload of manual computation and thus, to make the method more applicable. Second, the FAHP method with critiques on its subjective nature was adopted in this research to determine the weighing factors of the hazardous events that may happen. It is necessary for further studies to develop objective methods. The results comparison on risk assessment when using different methods would provide implications to the weights determination of the possible hazards, not only for Deep Foundation Pit, but for other construction projects as well.

\section{Acknowledgments}

This research was supported by the Construction Science and Technology Plan Project of Hubei Province under Grant No. HBJ2017-043 and also in part by the Key R \& D Program Projects in Shaanxi Province under Grant No. 2018ZDXM-SF-096. 
An, M., Chen, Y., \& Baker, C. J. (2011). A fuzzy reasoning and fuzzy-analytical hierarchy process based approach to the process of railway risk information : A railway risk management system. Information Sciences, 181(18), 3946-3966. https://doi.org/10.1016/j.ins.2011.04.051

An, M., Qin, Y., Jia, L. M., \& Chen, Y. (2016). Aggregation of group fuzzy risk information in the railway risk decision making process. Safety Science, 82, 18-28. https://doi.org/10.1016/j.ssci.2015.08.011

Bandeira, R. A. M., D’Agosto, M. A., Ribeiro, S. K., Bandeira, A. P. F., \& Goes, G. V. (2018). A fuzzy multicriteria model for evaluating sustainable urban freight transportation operations. Journal of Cleaner Production, 184, 727-739. https://doi.org/10.1016/j.jclepro.2018.02.234

Certa, A., Hopps, F., Inghilleri, R., \& Fata, C. M. La. (2017). A Dempster-Shafer Theory-based approach to the Failure Mode, E ff ects and Criticality Analysis ( FMECA ) under epistemic uncertainty : application to the propulsion system of a fi shing vessel. Reliability Engineering and System Safety, 159(October 2016), 6979. https://doi.org/10.1016/j.ress.2016.10.018

Cheng, H., She, J., Yuan, N., \& Peng, Z. (2016). Synthetic evaluation on risk of deep excavation engineering construction process. Journal of Tongji University (Natural Science)(In Chinese), 44(3), 491-498. https://doi.org/10.11908/j.issn.0253-374x.2016.03.024

Choi, H. H., Cho, H. N., \& Seo, J. W. (2004). Risk assessment methodology for underground construction projects. Journal of Construction Engineering and Management, 130(2), 258-272. https://doi.org/10.1061/(ASCE)0733-9364(2004)130:2(258)

Deng, Y., Sadiq, R., Jiang, W., \& Tesfamariam, S. (2011). Risk analysis in a linguistic environment : A fuzzy evidential reasoning-based approach. Expert Systems With Applications, 38(12), 15438-15446. 
Du, X., Zhang, X., Zhang, M., \& Hou, B. (2014). Risk synthetic assessment for deep pit construction based on evidence theory. Chinese Journal of Geotechnical Engineering(In Chinese), 36(1), 155-161. https://doi.org/10.11779/CJGE201401015

Goh, A. T.C. (2017). Deterministic and reliability assessment of basal heave stability for braced excavations with jet grout base slab. Engineering Geology, 218, 63-69. https://doi.org/10.1016/j.enggeo.2016.12.017

Goh, A. T.C., Kulhawy, F. H., \& Wong, K. S. (2008). Reliability assessment of Basal-Heave stability for braced excavations in clay. Journal of Geotechnical and Geoenvironmental Engineering, 134(2), 145-153. https://doi.org/10.1061/(ASCE)1090-0241(2008)134:2(145)

Goh, Anthony T.C., Zhang, W. G., \& Wong, K. S. (2019). Deterministic and reliability analysis of basal heave stability for excavation in spatial variable soils. Computers and Geotechnics, 108(July 2018), 152-160. https://doi.org/10.1016/j.compgeo.2018.12.015

Huang, H. wei, Zhang, Y. jie, Zhang, D. ming, \& Ayyub, B. M. (2017). Field data-based probabilistic assessment on degradation of deformational performance for shield tunnel in soft clay. Tunnelling and Underground Space Technology, 67(October 2016), 107-119. https://doi.org/10.1016/j.tust.2017.05.005

Jiang, W., Xie, C., Zhuang, M., \& Tang, Y. (2017). Failure mode and effects analysis based on a novel fuzzy evidential method. Applied Soft Computing Journal, 57, 672-683. https://doi.org/10.1016/j.asoc.2017.04.008

John, A., Paraskevadakis, D., Bury, A., Yang, Z., Riahi, R., \& Wang, J. (2014). An integrated fuzzy risk assessment for seaport operations. Safety Science, 68, 180-194. https://doi.org/10.1016/j.ssci.2014.04.001

Kim, K. O., \& Zuo, M. J. (2018). General model for the risk priority number in failure mode and effects analysis. Reliability Engineering and System Safety, 169(February 2017), 321-329. https://doi.org/10.1016/j.ress.2017.09.010 
602

603

604

605

606

607

608

609

610

611

612

613

614

615

616

617

618

619

620

621

622

623

Li, L. Y., Liu, Z., \& Wang, Z. H. (2018). Improved Analytic Hierarchy Process Based on Gray Correlation Model and Its Application in Pit Engineering. Journal of Beijing University of Technology (in Chinese), 44(6), 889-896. https://doi.org/10.11936/bjutxb2017040006

Li, S. cai, He, P., Li, L. ping, Shi, S. shuai, Zhang, Q. qing, Zhang, J., \& Hu, J. (2017). Gaussian process model of water inflow prediction in tunnel construction and its engineering applications. Tunnelling and Underground Space Technology, 69(February 2016), 155-161. https://doi.org/10.1016/j.tust.2017.06.018

Li, S. cai, Zhou, Z. qing, Li, L. ping, Xu, Z. hao, Zhang, Q. qing, \& Shi, S. shuai. (2013). Risk assessment of water inrush in karst tunnels based on attribute synthetic evaluation system. Tunnelling and Underground Space Technology, 38, 50-58. https://doi.org/10.1016/j.tust.2013.05.001

Li, Y., \& Liao, X. (2007). Decision support for risk analysis on dynamic alliance. Decision Support Systems, 42(4), 2043-2059. https://doi.org/10.1016/j.dss.2004.11.008

Liu, H. C., Liu, L., Bian, Q. H., Lin, Q. L., Dong, N., \& Xu, P. C. (2011). Failure mode and effects analysis using fuzzy evidential reasoning approach and grey theory. Expert Systems with Applications, 38(4), 4403-4415. https://doi.org/10.1016/j.eswa.2010.09.110

Liu, H. C., Liu, L., \& Liu, N. (2013). Risk evaluation approaches in failure mode and effects analysis: A literature review. Expert Systems with Applications, 40(2), 828-838. https://doi.org/10.1016/j.eswa.2012.08.010

Liu, H., Liu, L., \& Lin, Q. (2013). Fuzzy Failure Mode and Effects Analysis Using Fuzzy Evidential Reasoning and Belief Rule-Based Methodology. In IEEE Transactions on Reliability (Vol. 62, pp. 23-36). IEEE. https://doi.org/10.1109/TR.2013.2241251

Liu, J., Yang, J. B., Wang, J., \& Sii, H. S. (2005). Engineering system safety analysis and synthesis using the fuzzy rule-based evidential reasoning approach. Quality and Reliability Engineering International, 21(January), 387-411. https://doi.org/10.1002/qre.668 
624

Liu, X., Wang, Y., \& Li, D. Q. (2019). Investigation of slope failure mode evolution during large deformation in spatially variable soils by random limit equilibrium and material point methods. Computers and Geotechnics, 111(November 2018), 301-312. https://doi.org/10.1016/j.compgeo.2019.03.022

Markowski, A. S., \& Mannan, M. S. (2008). Fuzzy risk matrix. Journal of Hazardous Materials, 159(1), 152-157. https://doi.org/10.1016/j.jhazmat.2008.03.055

MoC. (2007). The subway and underground engineering construction risk management guidelines (In Chinese). Beijing: China Architecture \& Building Press.

Mokhtari, K., Ren, J., Roberts, C., \& Wang, J. (2012). Decision support framework for risk management on sea ports and terminals using fuzzy set theory and evidential reasoning approach. Expert Systems With Applications, 39(5), 5087-5103. https://doi.org/10.1016/j.eswa.2011.11.030

Ruiz-Padillo, A., Torija, A. J., Ramos-Ridao, A. F., \& Ruiz, D. P. (2016). Application of the fuzzy analytic hierarchy process in multi-criteria decision in noise action plans: Prioritizing road stretches. Environmental Modelling and Software, 81, 45-55. https://doi.org/10.1016/j.envsoft.2016.03.009

Samantra, C., Datta, S., \& Mahapatra, S. S. (2017). Fuzzy based risk assessment module for metropolitan construction project: An empirical study. Engineering Applications of Artificial Intelligence, 65(May), 449464. https://doi.org/10.1016/j.engappai.2017.04.019

Shafer, G. (2016). A Mathematical Theory of Evidence turns 40. International Journal of Approximate Reasoning, 79(November 1946), 7-25. https://doi.org/10.1016/j.ijar.2016.07.009

Valipour, A., Yahaya, N., Md Noor, N., Antuchevičienė, J., \& Tamošaitienė, J. (2017). Hybrid SWARA-COPRAS method for risk assessment in deep foundation excavation project: an Iranian case study. Journal of Civil Engineering and Management, 23(4), 524-532. https://doi.org/10.3846/13923730.2017.1281842 
Yang, J.B., Wang, Y. M., Xu, D. L., \& Chin, K. S. (2006). The evidential reasoning approach for MADA under both probabilistic and fuzzy uncertainties. European Journal of Operational Research, 171, 309-343. https://doi.org/10.1016/j.ejor.2004.09.017

Zadeh, L. A. (1965). Fuzzy sets. Information and Control, 8, 338-353.

Yang, Z., \& Wang, J. (2015). Use of fuzzy risk assessment in FMEA of offshore engineering systems. Ocean Engineering, 95, 195-204. https://doi.org/10.1016/j.oceaneng.2014.11.037

Yuen, K. K. (2014). Compound Linguistic Scale. Applied Soft Computing Journal, 21, 38-56. https://doi.org/10.1016/j.asoc.2014.02.012 https://doi.org/https://doi.org/10.1016/S0019-9958(65)90241-X https://doi.org/10.1016/j.ssci.2015.10.004 
Appendix: The derivation of $m_{1-\tilde{L}}\left\{\bar{H}_{n,(n+t)}\right\}$

672

673

674

675

676

677

678

679

680

681

682

683

684

685

686

687

688

689

690

Suppose that there is an intersection between each two sets among three consecutive fuzzy evaluation grades as shown in Fig. 11.

It is easy to prove that the equations of aggregated probability masses i.e. $m_{1-\tilde{L}}\left\{H_{n}\right\}, m_{1-\tilde{L}}\left\{\bar{H}_{n,(n+1)}\right\}$ and $\bar{m}_{1-\tilde{L}}\{H\}$ are the same with Eq. (17) Eq. (19) respectively. Readers can refer to (Yang et al., 2006) to acquire relevant contents about the proof. The expression of $m_{1-\tilde{L}}\left\{\bar{H}_{n,(n+t)}\right\}$ is displayed as follows:

$$
\begin{gathered}
m_{1-\tilde{L}}\left\{\bar{H}_{n,(n+t)}\right\}=k \mu_{H_{n,(n+t)}}^{\max }\left\{\prod_{j=1}^{\tilde{L}}\left[m_{j}\left\{H_{n}\right\}+m_{j}\left\{H_{n+t}\right\}+m_{j}\{H\}\right]-\prod_{j=1}^{\tilde{L}}\left[m_{j}\left\{H_{n}\right\}+m_{j}\{H\}\right]\right. \\
\left.-\prod_{j=1}^{\tilde{L}}\left[m_{j}\left\{H_{n+t}\right\}+m_{j}\{H\}\right]+\prod_{j=1}^{\tilde{L}} m_{j}\{H\}\right\} \\
n=1,2, \cdots, N-1, \quad t=1,2, \quad n+t \leq N
\end{gathered}
$$

\section{Proof:}

When $t=1, m_{1-\tilde{L}}\left\{\bar{H}_{n,(n+t)}\right\}=m_{1-\tilde{L}}\left\{\bar{H}_{n,(n+1)}\right\}$, the expression of which is the same with Eq. (18).

When $t=2$, the combined probability mass generated by aggregating the two attributes is given as follow:

$$
\begin{aligned}
& m_{1-2}\left\{H_{n,(n+2)}\right\}=m_{1}\left\{H_{n}\right\} m_{2}\left\{H_{n+2}\right\}+m_{2}\left\{H_{n}\right\} m_{1}\left\{H_{n+2}\right\} \\
& =\left[m_{1}\left\{H_{n}\right\}+m_{1}\left\{H_{n+2}\right\}\right]\left[m_{2}\left\{H_{n}\right\}+m_{2}\left\{H_{n+2}\right\}\right]-m_{1}\left\{H_{n}\right\} m_{2}\left\{H_{n}\right\}-m_{1}\left\{H_{n+2}\right\} m_{2}\left\{H_{n+2}\right\}
\end{aligned}
$$$$
=\left[m_{1}\left\{H_{n}\right\}+m_{1}\left\{H_{n+2}\right\}+m_{1}\{H\}\right]\left[m_{2}\left\{H_{n}\right\}+m_{2}\left\{H_{n+2}\right\}+m_{2}\{H\}\right]
$$$$
-\left[m_{1}\left\{H_{n}\right\}+m_{1}\{H\}\right]\left[m_{2}\left\{H_{n}\right\}+m_{2}\{H\}\right]
$$$$
-\left[m_{1}\left\{H_{n+2}\right\}+m_{1}\{H\}\right]\left[m_{2}\left\{H_{n+2}\right\}+m_{2}\{H\}\right]+m_{1}\{H\} m_{2}\{H\}
$$$$
=\prod_{j=1}^{2}\left[m_{j}\left\{H_{n}\right\}+m_{j}\left\{H_{n+2}\right\}+m_{j}\{H\}\right]-\prod_{j=1}^{2}\left[m_{j}\left\{H_{n}\right\}+m_{j}\{H\}\right]-\prod_{j=1}^{2}\left[m_{j}\left\{H_{n+2}\right\}+m_{j}\{H\}\right]+\prod_{j=1}^{2} m_{j}\{H\}
$$ 


$$
m_{1-(\tilde{L}-1)}\left\{H_{n,(n+2)}\right\}=\prod_{j=1}^{\tilde{L}-1}\left[m_{j}\left\{H_{n}\right\}+m_{j}\left\{H_{n+2}\right\}+m_{j}\{H\}\right]-\prod_{j=1}^{\tilde{L}-1}\left[m_{j}\left\{H_{n}\right\}+m_{j}\{H\}\right]
$$

$$
-\prod_{j=1}^{\tilde{L}-1}\left[m_{j}\left\{H_{n+2}\right\}+m_{j}\{H\}\right]+\prod_{j=1}^{\tilde{L}-1} m_{j}\{H\}
$$

694

The above combined probability mass is further aggregated with the $\tilde{L} t h$ attributes. The combined probability mass is then given below:

$$
\begin{gathered}
m_{1-\tilde{L}}\left\{H_{n,(n+2)}\right\}=m_{1-(\tilde{L}-1)}\left\{H_{n}\right\} m_{\tilde{L}}\left\{H_{n+2}\right\}+m_{\tilde{L}}\left\{H_{n}\right\} m_{1-(\tilde{L}-1)}\left\{H_{n+2}\right\} \\
=\left[m_{1-(\tilde{L}-1)}\left\{H_{n}\right\}+m_{1-(\tilde{L}-1)}\left\{H_{n+2}\right\}\right]\left[m_{\tilde{L}}\left\{H_{n}\right\}+m_{\tilde{L}}\left\{H_{n+2}\right\}\right] \\
-m_{1-(\tilde{L}-1)}\left\{H_{n}\right\} m_{\tilde{L}}\left\{H_{n}\right\}-m_{1-(\tilde{L}-1)}\left\{H_{n+2}\right\} m_{\tilde{L}}\left\{H_{n+2}\right\} \\
=\left[m_{1-(\tilde{L}-1)}\left\{H_{n}\right\}+m_{1-(\tilde{L}-1)}\left\{H_{n+2}\right\}+m_{1-(\tilde{L}-1)}\{H\}\right]\left[m_{\tilde{L}}\left\{H_{n}\right\}+m_{\tilde{L}}\left\{H_{n+2}\right\}+m_{\tilde{L}}\{H\}\right] \\
-\left[m_{1-(\tilde{L}-1)}\left\{H_{n}\right\}+m_{1-(\tilde{L}-1)}\{H\}\right]\left[m_{\tilde{L}}\left\{H_{n}\right\}+m_{\tilde{L}}\{H\}\right] \\
-\left[m_{1-(\tilde{L}-1)}\left\{H_{n+2}\right\}+m_{1-(\tilde{L}-1)}\{H\}\right]\left[m_{\tilde{L}}\left\{H_{n+2}\right\}+m_{\tilde{L}}\{H\}\right]+m_{1-(\tilde{L}-1)}\{H\} m_{\tilde{L}}\{H\} \\
=\prod_{j=1}^{\tilde{L}-1}\left[m_{j}\left\{H_{n}\right\}+m_{j}\left\{H_{n+2}\right\}+m_{j}\{H\}\right]\left[m_{\tilde{L}}\left\{H_{n}\right\}+m_{\tilde{L}}\left\{H_{n+2}\right\}+m_{\tilde{L}}\{H\}\right] \\
-\prod_{j=1}^{\tilde{L}-1}\left[m_{j}\left\{H_{n}\right\}+m_{j}\{H\}\right]\left[m_{\tilde{L}}\left\{H_{n}\right\}+m_{\tilde{L}}\{H\}\right]
\end{gathered}
$$

$$
\begin{aligned}
& -\prod_{j=1}^{\tilde{L}-1}\left[m_{j}\left\{H_{n+2}\right\}+m_{j}\{H\}\right]\left[m_{\tilde{L}}\left\{H_{n+2}\right\}+m_{\tilde{L}}\{H\}\right]+\prod_{j=1}^{\tilde{L}-1} m_{j}\{H\} m_{\tilde{L}}\{H\} \\
& =\prod_{j=1}^{\tilde{L}}\left[m_{j}\left\{H_{n}\right\}+m_{j}\left\{H_{n+2}\right\}+m_{j}\{H\}\right]-\prod_{j=1}^{\tilde{L}}\left[m_{j}\left\{H_{n}\right\}+m_{j}\{H\}\right] \\
& -\prod_{j=1}^{\tilde{L}}\left[m_{j}\left\{H_{n+2}\right\}+m_{j}\{H\}\right]+\prod_{j=1}^{\tilde{L}} m_{j}\{H\}
\end{aligned}
$$

Since the fuzzy subset $H_{n,(n+2)}$ is the intersection of the two fuzzy evaluation grades $H_{n}$ and $H_{n+2}$, its maximum degree of membership is normally not equal to 1 . In order to capture the exact probability mass assigned to $H_{n,(n+2)}$, its membership function needs to be normalized(Yang et al., 2006):

$$
m_{1-\tilde{L}}\left\{\bar{H}_{n,(n+2)}\right\}=k \mu_{H_{n,(n+2)}}^{\max }\left\{\prod_{j=1}^{\tilde{L}}\left[m_{j}\left\{H_{n}\right\}+m_{j}\left\{H_{n+2}\right\}+m_{j}\{H\}\right]-\prod_{j=1}^{\tilde{L}}\left[m_{j}\left\{H_{n}\right\}+m_{j}\{H\}\right]\right.
$$




$$
\left.-\prod_{j=1}^{\tilde{L}}\left[m_{j}\left\{H_{n+2}\right\}+m_{j}\{H\}\right]+\prod_{j=1}^{\tilde{L}} m_{j}\{H\}\right\}
$$

713 Where $k$ can be determined using the following normalization constraint condition:

$$
\sum_{n=1}^{N} m\left\{H_{n}\right\}+\sum_{i=1}^{2} \sum_{n=1}^{N-t} m\left\{\bar{H}_{n,(n+t)}\right\}+m\{H\}=1
$$

715 From the above equation, it can be received:

716

$$
k=\left\{\sum_{n=1}^{N}\left\{\prod_{j=1}^{\tilde{L}}\left[m_{j}\left\{H_{n}\right\}+m_{j}\{H\}\right]-\prod_{j=1}^{\tilde{L}} m_{j}\{H\}\right\}\right.
$$

$+\sum_{t=1}^{2} \sum_{n=1}^{N-t} \mu_{H_{n,(n+t)}}^{\max }\left\{\prod_{j=1}^{\tilde{L}}\left[m_{j}\left\{H_{n}\right\}+m_{j}\left\{H_{n+t}\right\}+m_{j}\{H\}\right]-\prod_{j=1}^{\tilde{L}}\left[m_{j}\left\{H_{n}\right\}+m_{j}\{H\}\right]\right.$

$\left.\left.-\prod_{j=1}^{\tilde{L}}\left[m_{j}\left\{H_{n+t}\right\}+m_{j}\{H\}\right]+\prod_{j=1}^{\tilde{L}} m_{j}\{H\}\right\}+\prod_{j=1}^{\tilde{L}} m_{j}\{H\}\right\}^{-1}$

719 Suppose there is an intersection between each two sets among $\mathrm{N}$ consecutive fuzzy evaluation grades as shown in Fig. 12.

721 In this case, the expression of $m_{1-\tilde{L}}\left\{H_{n,(n+t)}\right\}$ is the same with Eq. (35), but the value of $t$ is defined as: $t=1,2, \cdots, \mathrm{N}-1$, and $n+t \leq \mathrm{N}$, the process of proof ibids.

$$
\sum_{n=1}^{N} m\left\{H_{n}\right\}+\sum_{t=1}^{N-1} \sum_{n=1}^{N-t} m\left\{\bar{H}_{n,(n+t)}\right\}+m\{H\}=1
$$

From which it can be obtained:

726

$$
k=\left\{\sum_{n=1}^{N}\left\{\prod_{j=1}^{\tilde{L}}\left[m_{j}\left\{H_{n}\right\}+m_{j}\{H\}\right]-\prod_{j=1}^{\tilde{L}} m_{j}\{H\}\right\}\right.
$$

$$
+\sum_{t=1}^{N-1} \sum_{n=1}^{N-t} \mu_{H_{n,(n+t)}}^{\max }\left\{\prod_{j=1}^{\tilde{L}}\left[m_{j}\left\{H_{n}\right\}+m_{j}\left\{H_{n+t}\right\}+m_{j}\{H\}\right]-\prod_{j=1}^{\tilde{L}}\left[m_{j}\left\{H_{n}\right\}+m_{j}\{H\}\right]\right.
$$

$$
\left.\left.-\prod_{j=1}^{\tilde{L}}\left[m_{j}\left\{H_{n+t}\right\}+m_{j}\{H\}\right]+\prod_{j=1}^{\tilde{L}} m_{j}\{H\}\right\}+\prod_{j=1}^{\tilde{L}} m_{j}\{H\}\right\}^{-1}
$$


Fig.1.

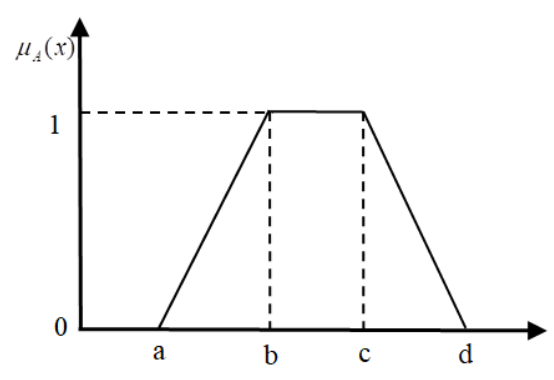

Fig.1 A trapezoidal fuzzy number

Fig. 2.

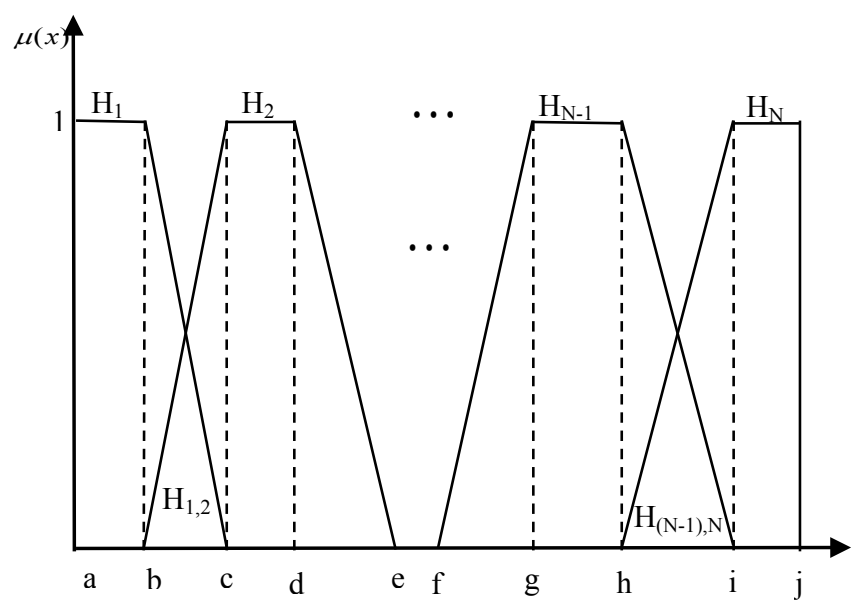

Fig.2 Intersection exists between two adjacent fuzzy assessment grades

Fig. 3

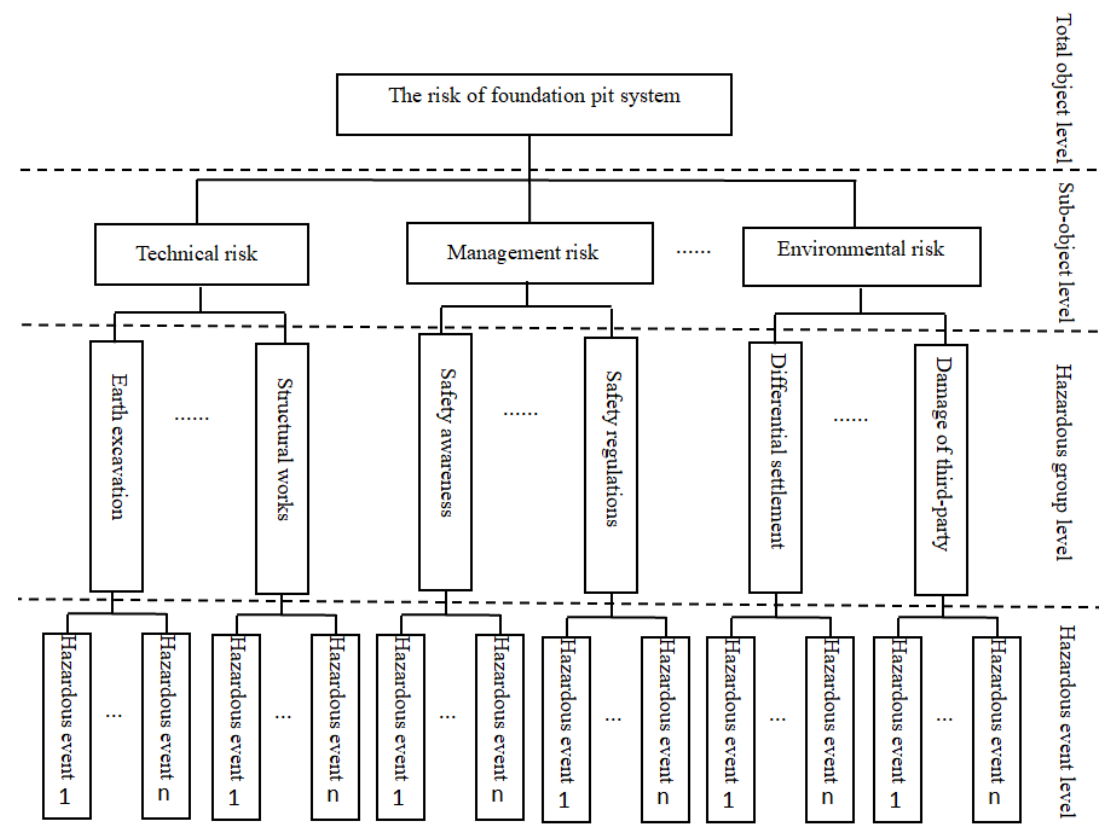

Fig.3 A typical risk framework of DFP 
Fig. 4.

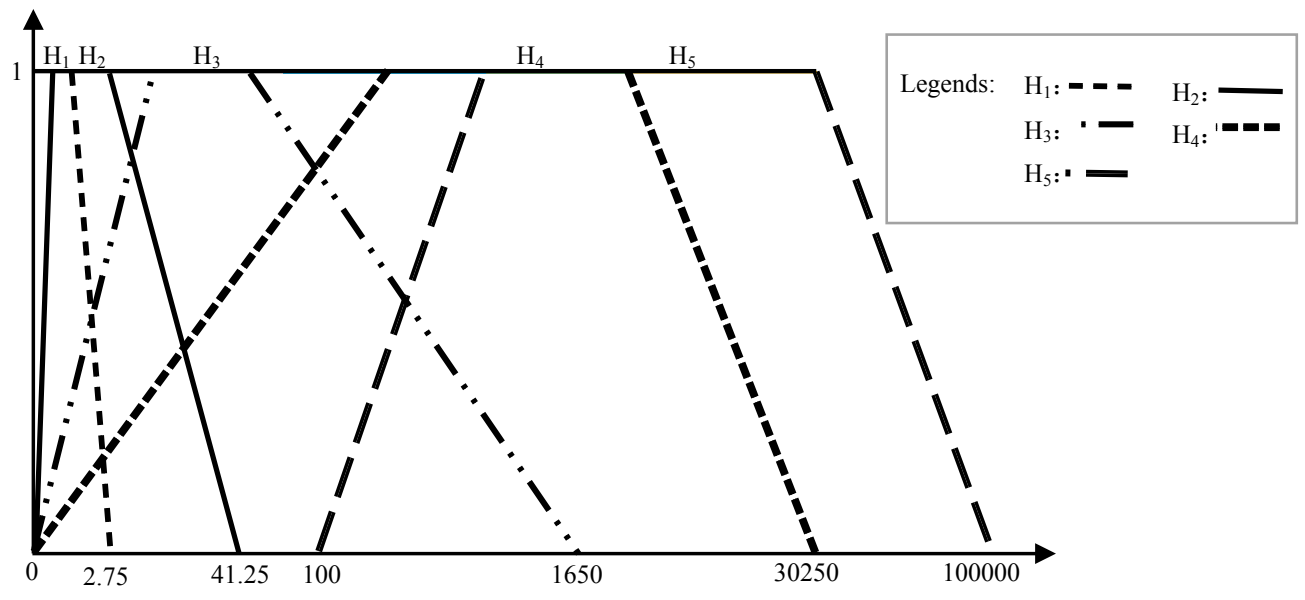

Fig.4 Curves of membership function with respect to risk grades

Fig.5.

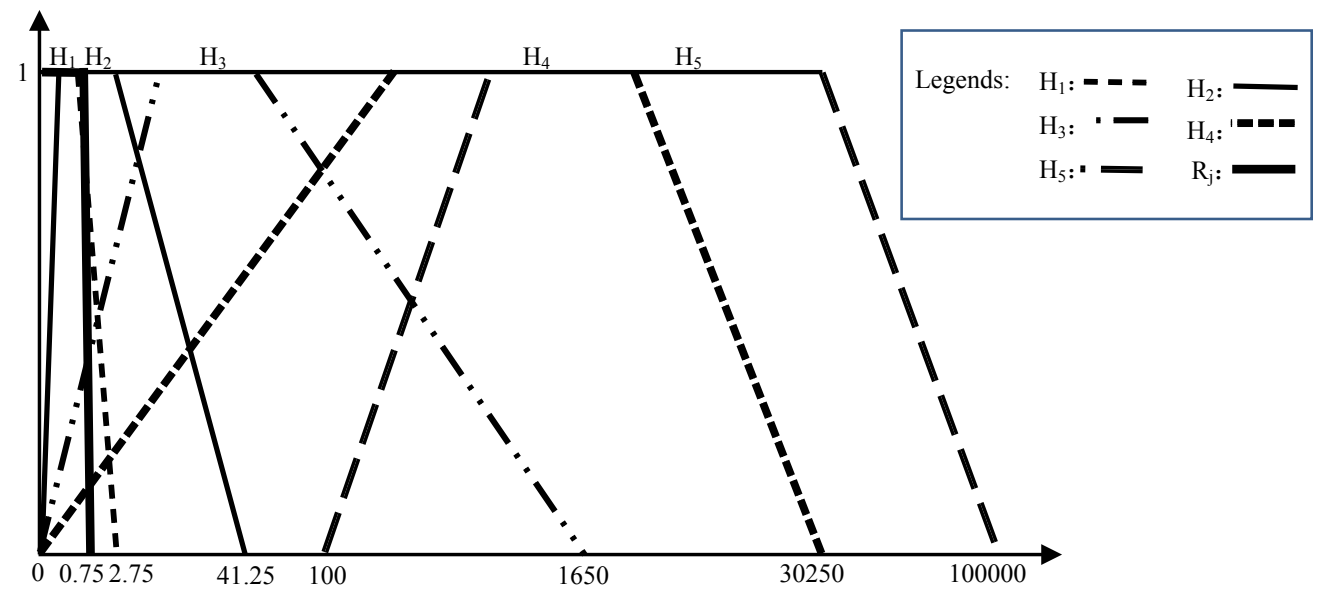

Fig. 5 Location of $R_{j}$ in curves of membership function

Fig. 6a.

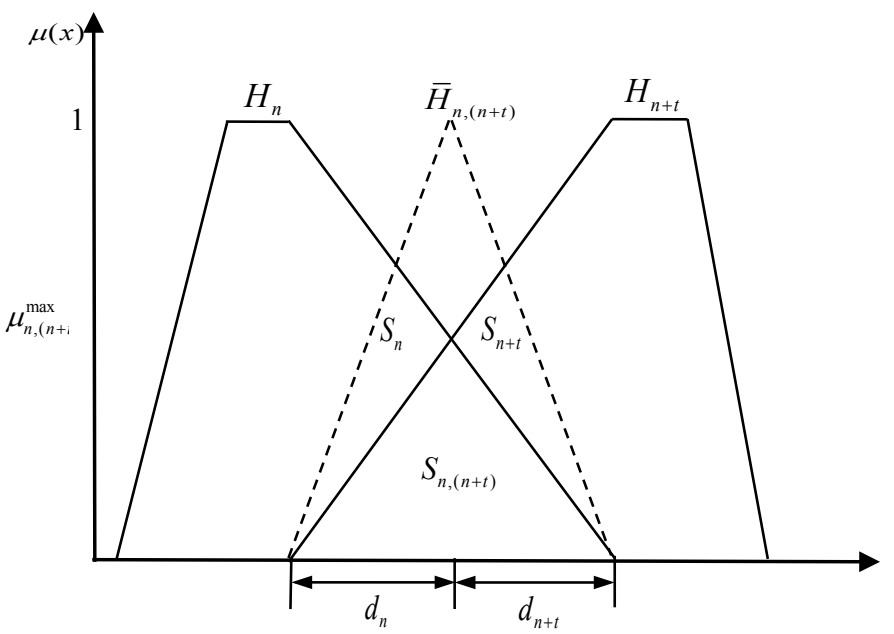

Fig.6a Redistribution of $\beta_{n,(n+t)}$ as maximum membership is less than one 
Fig. 6b.

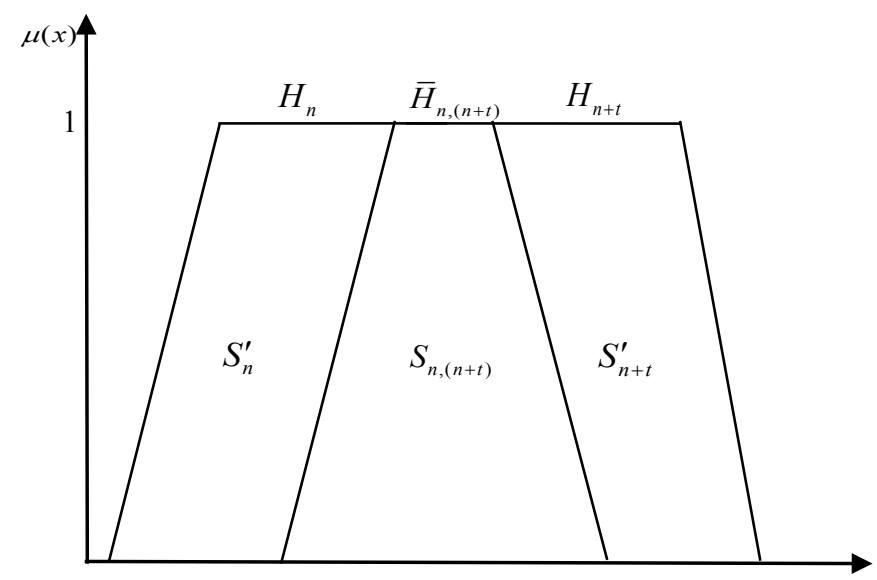

Fig.6b Redistribution of $\beta_{n,(n+t)}$ as maximum membership equals to one

Fig. 7.

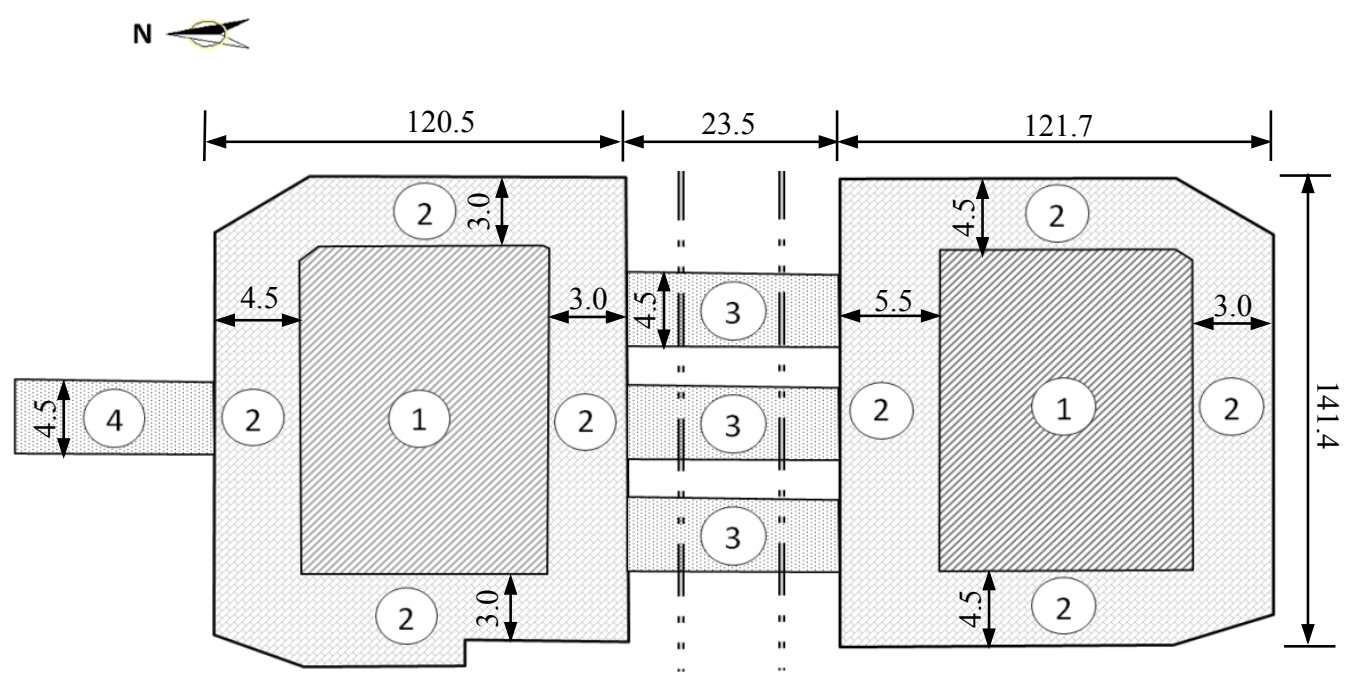

Notes: (1)Area used Bottom-Up Method; (2)Area used Top-Down Method; (3)

Connecting passage; (4)Connecting passage of north entrance; Unit: meter

Fig.7 Construction division of the DFP 
Fig. 8

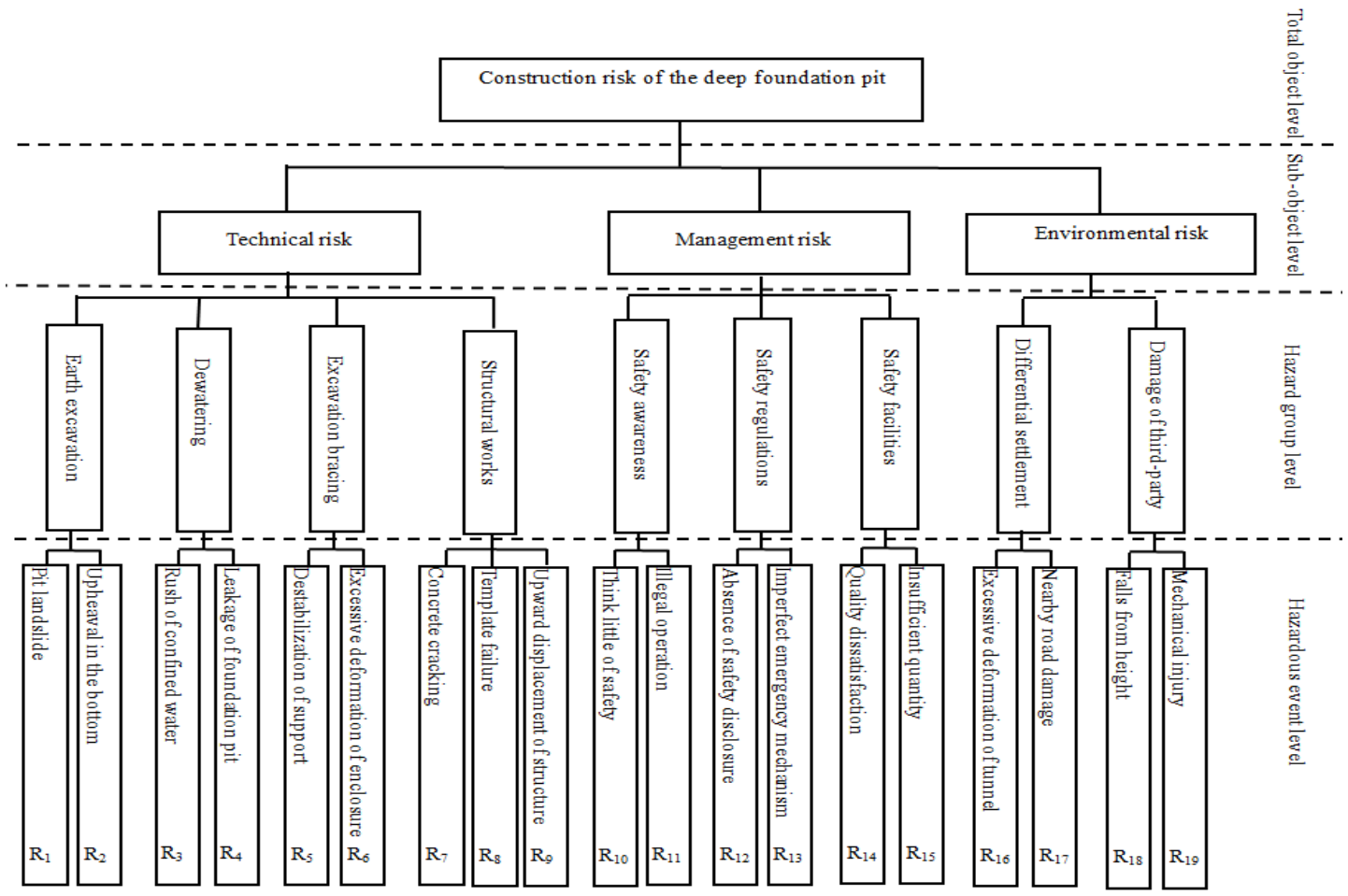

Fig.8 Risk framework developed under this DFP construction project

Fig.9.

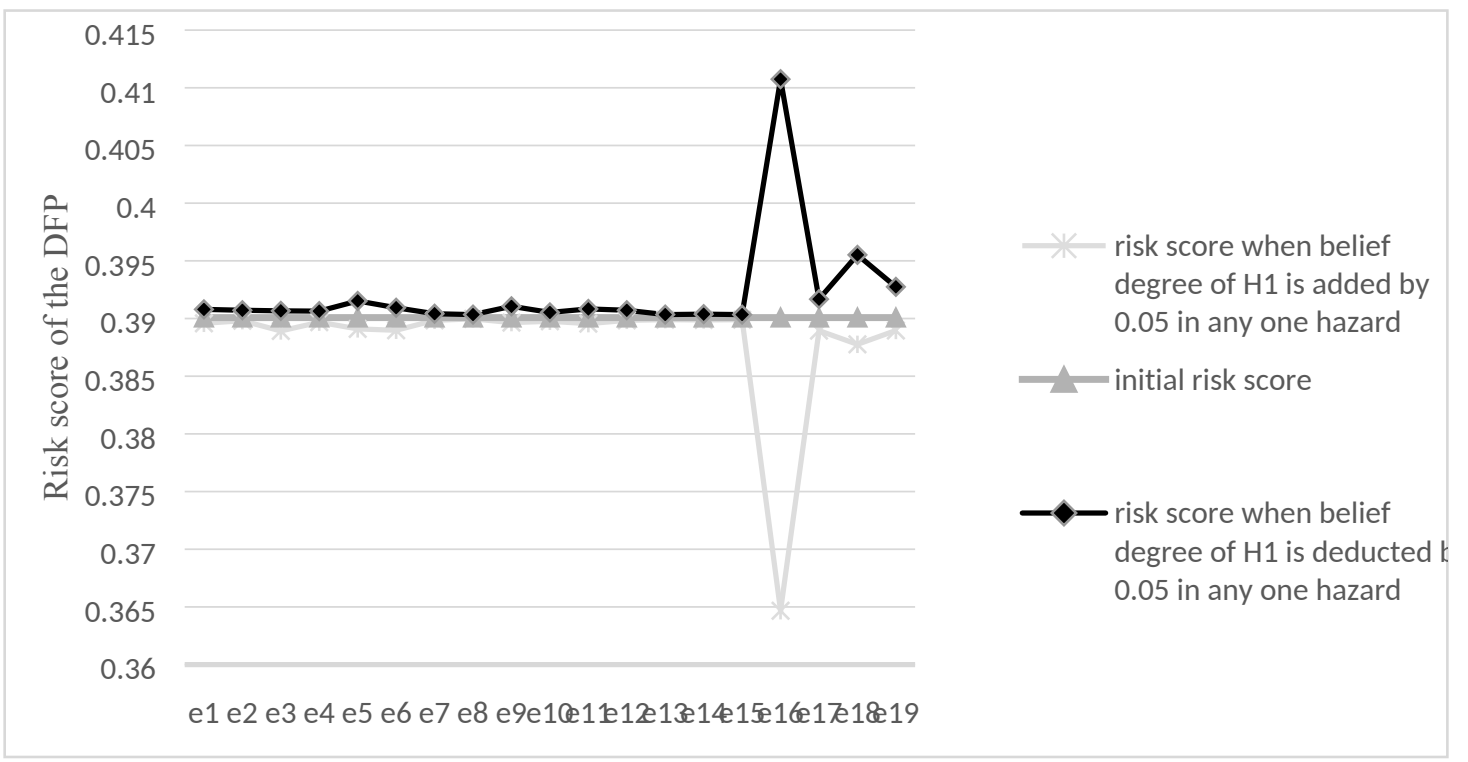

Fig.9 The variation of overall risk score as the belief structure of each hazard varied in turn Fig. 10.

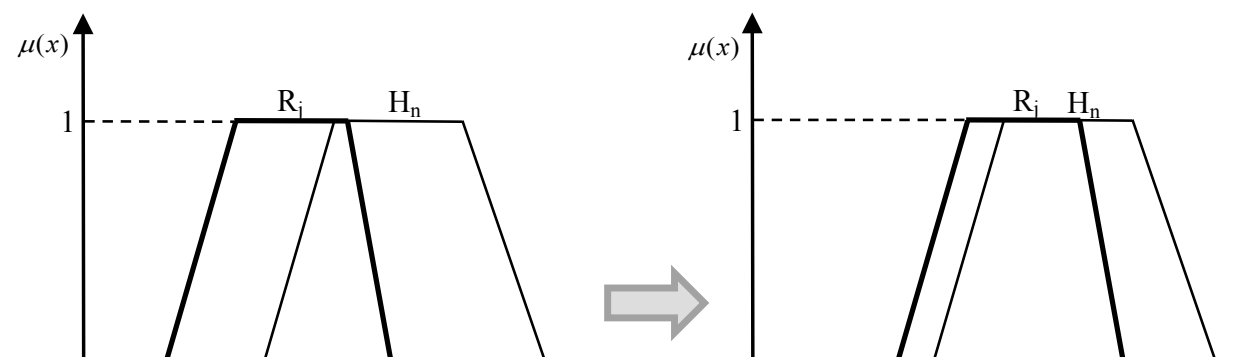


Fig. 9 Comparison of the location between hazard $R_{j}$ and risk grade $H_{n}$

Fig. 11.

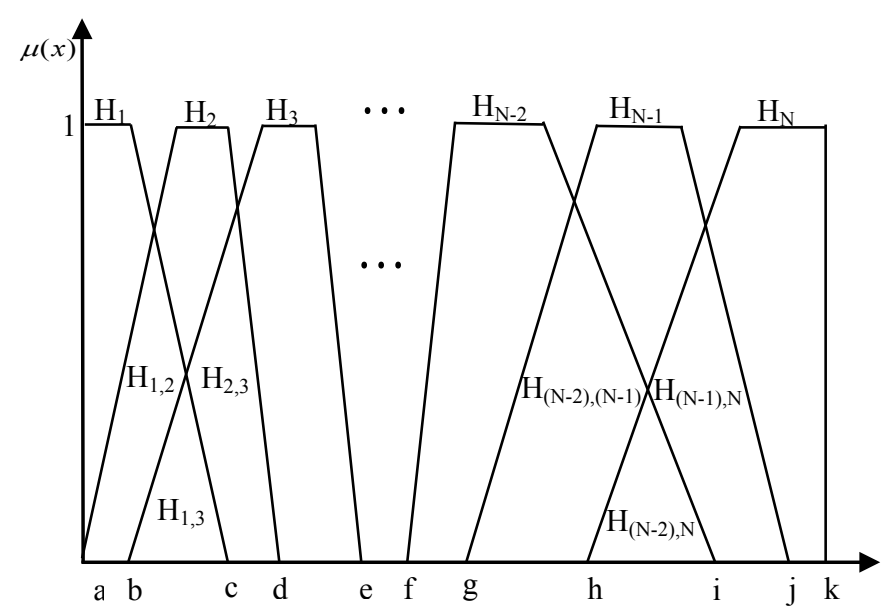

Fig.11 Intersection exists between each two sets among three consecutive fuzzy assessment grades

Fig. 12.

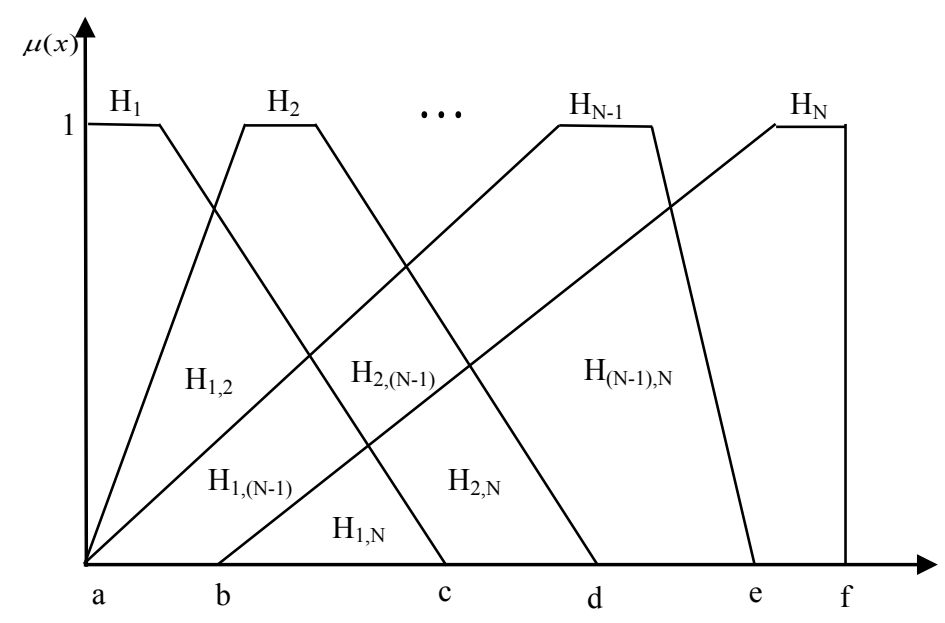

Fig.12 Intersection exists between each two sets among $\mathbf{N}$ fuzzy assessment grades 